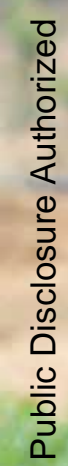

这

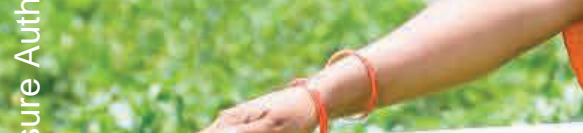

कo

a.

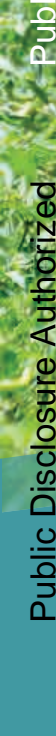

Making Climate Finance Work in Agriculture

Discussion Paper

\#) WORLD BANKGROUP

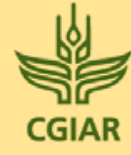

RESEARCH PRogram ON

Agriculture and

Food Security

(C)

N1

CGIAR

CCAFS

UKaid 



\title{
Making Climate Finance Work in Agriculture
}

\author{
Discussion Paper
}




\section{Standard Disclaimer:}

This volume is a product of the staff of the International Bank for Reconstruction and Development/ The World Bank. The findings, interpretations, and conclusions expressed in this paper do not necessarily reflect the views of the Executive Directors of The World Bank or the governments they represent. The World Bank does not guarantee the accuracy of the data included in this work. The boundaries, colors, denominations, and other information shown on any map in this work do not imply any judgment on the part of The World Bank concerning the legal status of any territory or the endorsement or acceptance of such boundaries.

This material has also been funded by the U.K. government through UKAid; however, the views expressed here do not necessarily reflect official U.K. policies.

This work was partly funded and conducted by the International Center for Tropical Agriculture (CIAT) as part of the CGIAR Research Program on Climate Change, Agriculture and Food Security (CCAFS). CCAFS brings together some of the world's best researchers in agricultural science, development issues, climate science, and Earth System science, to identify and address the most important interactions, synergies, and trade-offs between climate change, agriculture, and food security. The views expressed in this document are not necessarily endorsed by or representative of CCAFS, CIAT, or of the cosponsoring or supporting organizations.

\section{Copyright Statement:}

The material in this publication is copyrighted. Copying and/or transmitting portions or all of this work without permission may be a violation of applicable law. The International Bank for Reconstruction and Development/ The World Bank encourages dissemination of its work and will normally grant permission to reproduce portions of the work promptly.

For permission to photocopy or reprint any part of this work, please send a request with complete information to the Copyright Clearance Center, Inc., 222 Rosewood Drive, Danvers, MA 01923, USA, telephone 978-750-8400, fax 978-7504470, http://www.copyright.com/.

All other queries on rights and licenses, including subsidiary rights, should be addressed to the Office of the Publisher, The World Bank, 1818 H Street NW, Washington, DC 20433, USA, fax 202-522-2422, e-mail pubrights@worldbank.org

Cover photo courtesy of Neil Palmer (CIAT). 


\section{CONTENTS}

Acknowledgments

Acronyms and Abbreviations vii

Overview

Chapter 1 Agriculture and Climate Change

Agriculture: Part of the Problem, Part of the Solution 1

A Unique Opportunity to Leverage Climate Finance for Agriculture 3

Notes

Chapter 2 Financing Climate-Smart Interventions in Agriculture 5

Traditional Constraints on Financing for Agriculture $\quad 5$

$\begin{array}{ll}\text { The Main Barriers to Lending to Agriculture } & 6\end{array}$

How Climate Finance Relates to Agricultural Finance $\quad 9$

Scope of Climate Finance 9

Overview of Climate Finance Architecture 11

Role of Climate Finance in Agriculture 12

Barriers Preventing Climate Finance from Flowing into Agriculture 13

$\begin{array}{ll}\text { Notes } & 14\end{array}$

Chapter 3 Leveraging Climate Finance to Make Agriculture Part of the Solution 15

Innovative Ways to Attract Additional Capital to Agriculture 16

$\begin{array}{lr}\text { Climate Finance Entry Points into Agriculture } & 18\end{array}$

$\begin{array}{ll}\text { Improving the Enabling Environment } & 19\end{array}$

Risk Management Mechanisms $\quad 23$

Mechanisms to Reduce Transaction Costs 32

Technical Assistance to Increase Investments in Agriculture 34

Technical Assistance to Lenders 34

Building Borrower Capacity 36

$\begin{array}{ll}\text { Notes } & 37\end{array}$

Chapter 4 Conclusion and Way Forward 39

$\begin{array}{ll}\text { References } & 41\end{array}$ 


\section{Boxes}

2.1 From Financing Agriculture to Financing Climate-smart Investments in Agriculture 9

2.2. "Climate Finance" in this Paper 9

2.3 The Global Agriculture and Food Security Program (GAFSP) 12

3.1 Peru Case Study: Global Canopy Program - Unlocking Forest Finance 18

3.2 The eco.business Fund Case Study 19

3.3 Ecuador Case Study: Credit Bureaus for the Rural Poor 24

3.4 Ethiopia Case Study: Farmers Access Finance Through Credit Guarantee Services 25

3.5 Kenya Case Study: Input-linked Weather Insurance - Syngenta Foundation and UAP Insurance 27

3.6 India Case Study: Value Chain Finance - HDFC Bank 29

3.7 India Case Study: Warehouse Receipt Financing - HDFC Bank 29

3.8 Philippines Case Study: Climate-smart Rice Cultivation through Phone Apps 30

3.9 Big Data Case Study: Reaching Smallholders with Alternative Credit Assessments 31

3.10 Pakistan Case Study: Branchless Banking - United Bank Ltd. 33

3.11 Kenya Case Study: Mobile Banking - M-PESA and M-KESHO 34

3.12 Cambodia Case Study: Building Agricultural Lending Skills - Amret Microfinance Institution and the World Bank

\section{Figures}

$2.1 \quad$ Key Barriers to Lending $\quad 7$

2.2 Risk Profiles along the Agricultural Value Chain 8

3.1 Multiplier Effect of PPPs 16

$\begin{array}{lll}3.2 & \text { Examples of Layered Capital Structures } & 17\end{array}$

3.3 Sample Finance Model for Finance in Motion 18

3.4 Example of a Climate-smart Investment Facilitator and Climate-smart Incubator 21

3.5 Example of a Climate-smart Investment Facilitator and Climate-smart Incubator 22

3.6 Portfolio Tranching to Segment Risk Types 26 


\section{ACKNOWLEDGMENTS}

Making Climate Finance Work in Agriculture is the outcome of a collaborative approach between the World Bank (WB) Global Practice for Food and Agriculture; the CGIAR Research Program on Climate Change, Agriculture and Food Security (CCAFS); and the U.K. Department for International Development (UK DFID).

This discussion paper was prepared by a team led by Marc Sadler (Global Lead for Climate Smart Agriculture, WB), and comprising Alberto Millan (Agricultural Specialist, WB), Stacy A. Swann (Consultant), Ioannis Vasileiou (Agricultural Specialist, WB), Tobias Baedeker (Agriculture Economist, WB), Roy Parizat (Senior Economist, WB), Leah Arabella Germer (Consultant), and Friederike Mikulcak (Junior Professional Officer, WB).

The team is also grateful to Preeti Ahuja (Practice Manager, WB) for her valuable guidance and support. Kruskaia Sierra-Escalante (Head, Climate Change Blended Finance, IFC), Panayotis N. Varangis (Global Lead for Agriculture Finance and Agriculture Insurance, WB), Juan Buchenau (Senior Financial Sector Specialist, WB), and Christopher James
Warner (Senior Natural Resources Management Specialist, WB) kindly peer-reviewed the discussion paper and provided very insightful suggestions. The team is also grateful to David Howlett (DFID), Leslie Lipper (FAO), and Astrid Agostini (FAO) for their valuable contributions.

A wide range of people and organizations in the agriculture, climate and finance sectors generously contributed case studies and valuable inputs; among them were Jamie Anderson (CGAP), Michael Andrade (HDFC Bank, India), Simone Bauch, Josh Gregory and Alexandra Pinzon (Global Canopy Programme), Eric Cochard (Credit Agricole), Lauren Hendricks and Dorcas Robinson (CARE USA), Aitor Ezcurra (IFC), the WB GAFSP Team, Brian Milder and Elizabeth Teague (Root Capital), James Rawles (CCAFS), Elena Yunatska (Finance in Motion), and Dan Zook (Initiative for Smallholder Finance).

This work was funded by the World Bank, the CGIAR Research Program on Climate Change, Agriculture and Food Security (CCAFS), and with UK Aid from the UK Government. 



\section{ACRONYMS AND ABBREVIATIONS}

\begin{tabular}{|c|c|}
\hline AFOLU & Agriculture, Forestry, and Other Land Use \\
\hline ATM & Automated Teller Machine \\
\hline BDSC & Big Data, Small Credit \\
\hline $\mathrm{CBO}$ & Congressional Budget Office \\
\hline CDM & Clean Development Mechanism \\
\hline CCAFS & Research Program on Climate Change, Agriculture, and Food Security \\
\hline CEDISA & Centro de Desarrollo e Investigación de la Selva Alta \\
\hline CIF & Climate Investment Fund \\
\hline CFC & Cooperative Finance Corporation \\
\hline $\mathrm{COP}$ & Conference of the Parties \\
\hline CPI & Climate Policy Initiative \\
\hline CSA & Climate-Smart Agriculture \\
\hline DFI & Development Finance Institution \\
\hline DFID & Department for International Development, U.K. \\
\hline FI & Financial Institution \\
\hline GAFSP & Global Agriculture and Food Security Program \\
\hline GCF & Green Climate Fund \\
\hline GDP & Gross Domestic Product \\
\hline GEF & Global Environment Facility \\
\hline GHG & Greenhouse Gas \\
\hline GIIF & Global Index Insurance Facility \\
\hline ICT & Information and Communications Technology \\
\hline IFC & International Finance Corporation \\
\hline IFI & International Finance Institutions \\
\hline INDC & Intended Nationally Determined Contribution \\
\hline IPCC & Intergovernmental Panel on Climate Change \\
\hline MDB & Multilateral Development Bank \\
\hline MNO & Mobile Network Operator \\
\hline NDC & Nationally Determined Contribution \\
\hline NGO & Nongovernmental Organization \\
\hline OCT & Over-the-Counter Transaction \\
\hline OECD & Organisation for Economic Co-operation and Development \\
\hline POS & Point of Sale \\
\hline PPCR-CIF & Pilot Program for Climate Resilience, Climate Investment Fund \\
\hline
\end{tabular}


PPP Public-Private Partnership

REDD+ Reducing Emissions from Deforestation and Forest Degradation

SCCF-GEF Special Climate Change Fund (SCCF) of the Global Environment Facility

SDG Sustainable Development Goal

SME Small and medium enterprise

SOFA FAO State of Food and Agriculture report

UFF Unlocking Foreign Finance project

UN United Nations

UNFCCC United Nations Framework Convention on Climate Change

USAID United States Agency for International Development

VCF

Value Chain Finance

WB World Bank 


\section{OVERVIEW}

This discussion paper was produced as a background document for the 2016 FAO State of Food and Agriculture (SOFA) report. It is based on in-depth analysis of the agriculture and climate finance literature, as well as interviews with key experts representing various stakeholder groups in the agriculture, climate, and finance sectors. The interviews were conducted in order to identify those opportunities and innovations that should be explored to make climate finance work for agriculture. Innovative and successful examples of current efforts by the climate finance community to reach agriculture have been provided by a range of relevant stakeholders.

This discussion paper explores the intersection between climate and agriculture finance by promoting dialogue about these topics and suggesting innovative approaches. Exploration of this intersection is relatively new, and the interventions explored here either are being tested or could be tested to increase the leverage of private capital and strengthen the links of financial institutions (FIs) with smallholder farmers and small and medium enterprises (SMEs). Because the objective is to generate discussion, no blanket recommendations or descriptive interventions are proposed.

Today a growing population and changing diets are driving an increased demand for food. Production is struggling to keep up as crop yields level off in many parts of the world, ocean health declines, and natural resources-such as soils, water, and biodiversity-are stretched dangerously thin. One in eight people suffers from chronic hunger and more than one billion people are undernourished. The food security challenge will only get more difficult because by 2050 the world will need to produce at least 50 percent more food to feed nine billion people. Climate change adds significant challenges to this already perilous situation.

However, agriculture in developing countries can offer a pathway to economic development and inclusive growth. Recently the Economist estimated that by 2030, with the right policies and investments, agriculture could unlock an extra US\$2 trillion in rural growth. Much of the growth could benefit smallholder farmers in developing countries where, especially in Africa, agriculture is likely to be the main source of people's livelihoods for the next several decades. To realize the opportunities agriculture has to offer, the sector needs to be transformed so it can deliver more sustainable agriculture and smallholder farmers can access markets and become successful and profitable while also delivering food and nutrition security. Here, agriculture has the potential to become:

- A thriving and successful sector that creates jobs and provides economic and livelihood benefits;

- A resilient sector that can successfully manage the climate risks of today and tomorrow; and

- A sustainable sector that minimizes its environmental impacts.

Moreover, taking the right action on agriculture can also help to significantly empower women, because at least 70 percent of women in South Asia and 60 percent in Sub-Saharan Africa work in agriculture.

Climate change and agriculture are critically interrelated. Agriculture is extremely vulnerable to climate change: the sensitivity of crops, livestock, and fisheries to temperature, water availability, and extreme weather events puts yields at risk, 
jeopardizes historical productivity gains, and exposes farmers to significant hazards. Because yields affect their incomes, food security, and livelihoods, farmers are the first to be confronted with the perils associated with climate change impacts on agriculture. Yet agriculture also contributes to climate change; it accounts for 19 to 29 percent of total greenhouse gas (GHG) emissions and emits the largest share of non- $\mathrm{CO}_{2}$ GHGs. Thus, farmers and other actors across the agricultural value chain have a crucial role in achieving a global climate solution.

Fortunately, research has shown that climate change adaptation and mitigation in the agricultural sector are feasible both technically and economically. Agriculture is thus prominent in the recent Paris Agreement, the Intended Nationally Determined Contributions (INDCs), and the Sustainable Development Goals (SDGs).

Specifically, the outcomes of the December 2015 Conference of the Parties (COP21) to the UNFCCC in Paris, laid a solid foundation for global action to adapt and mitigate the effects of climate change on agriculture. The majority of the INDCs include agriculture in their mitigation targets or reference agriculture as an adaptation priority. Those ambitions are also tightly linked to many of the SDGs, particularly SDG 1 (no poverty), SDG 2 (zero hunger), and SDG 13 (climate action). Still, in most cases cost estimates and adequate financial mechanisms have yet to be specified. Equally critical to achieving these adaptation and mitigation objectives is significantly increasing the amount of capital available for climate-smart investments in agriculture, which will require overcoming long-standing institutional barriers.

The need for additional liquidity in agriculture is not new. Access to sufficient and adequate finance has been a challenge for agriculture in developing countries for decades. Due to perceptions of its low profitability, low margins for financiers, and high actual and perceived risks (among other issues) financiers in most countries limit their exposure, raise interest rates, tighten lending criteria, shorten terms, impose onerous lending terms, and often shy away from lending to agriculture at all, seeking more stable returns from other sectors of the economy. This finance shortfall is a major problem for smallholder farmers and SME agribusinesses, particularly for women, who have the least access to finance.

Three of the major barriers that have traditionally limited the access of smallholder farmers and SMEs to sufficient and adequate finance are:
- Inadequate enabling environments;

- Insufficient capacity to manage exposure to specific agricultural risks; and

- High transaction costs.

These continue to limit the access of farmers to working capital (short-term loans) and more importantly to investment capital (longer-term loans), making it difficult for them to invest in the valueadding infrastructure that could dramatically raise their productivity and incomes. These barriers also limit the access of smallholder farmers and SMEs to a broad range of other tailored and demand-driven financial services. According to the Initiative for Smallholder Finance, total smallholder financing demand in Latin America, Sub-Saharan Africa, and South and South East Asia is estimated at $\$ 210$ billion (Dalberg 2014). With 75 percent of the world's poorest people located in rural agricultural areas, this gap is a severe impediment to poverty reduction.

Despite agriculture's vulnerability to climate change, the total amount of climate finance allocated in 2014 to agriculture, forestry, and other land-use was disproportionally small at US $\$ 6-8$ billion, considering that the total amount of climate finance mobilized globally that year was US\$391 billion. Among the factors responsible for the shortfall are imbalanced risk-reward profiles for investments in the sector, limited capacity to identify financial needs for adaptation and mitigation purposes in agriculture, an evidence base that is insufficient for identifying the most suitable climate-smart practices and technologies, a lack of adequate metrics and tools to accurately measure the impact of climatesmart interventions, and a fragmentation of climate finance resources.

However, climate finance can be instrumental in supporting the agriculture sector to become part of the climate solution. This discussion paper proposes three avenues for making this happen:

\section{Design innovative mechanisms and adapt oth-} ers to leverage additional sources of both public and private capital that can be directed toward climate-smart investments in agriculture. This discussion paper discusses such mechanisms as:

- Enhancing public-private partnerships to leverage the resources, expertise, and capacities of different stakeholders;

- Designing and piloting new investment vehicles that can attract additional capital by 
diversifying, managing and rebalancing the risk return profiles of individual investors; and

- Bundling a wide range of financial instruments to heighten their effectiveness and provide more holistic and comprehensive solutions.

However additional investments alone will not be effective. The entrance of climate finance into agriculture will be impeded by the same old constraints unless they are addressed while also achieving positive climate outcomes. To ensure that additional capital is effective, it is essential to strengthen the currently tenuous links between FIs and farmers. To that end, the second avenue to using climate finance discussed here will be critical.

2. Identify entry points, for directing climate finance into agriculture and linking financial institutions smallholders and agricultural SMEs. Public sources of climate finance are uniquely positioned to address some of the financial sector constraints on agriculture and thus significantly increase the flows of capital to smallholder farmers and SMEs. For instance, climate finance could be used for:

- Developing and improving a finance-enabling environment for agriculture: The basis could be better policies and regulations to mobilize and channel financial flows to farmers and to build the structures to facilitate and accelerate climate-smart and other investments;

- Supporting FIs to develop and reinforce their risk management mechanisms: Possible options are to establish rural credit-rating agencies, and promote guarantees, insurance, value-chain finance, warehouse receipts, climate-smart advisory services, and big data and data science; and

- Supporting FIs to reduce transaction costs: Branchless banking and mobile financial services are the most obvious of numerous options.

These interventions could significantly help FIs to enhance their capacity to design and provide tailored financial instruments and develop new delivery channels that meet the needs of those smallholder farmers and SMEs engaged in climate-smart practices. Moreover, financial and technical support could be contingent upon achieving specific climate-smart outcomes, so that FIs specifically promote such investments after an earlier technical assistance program. To achieve this, it will be crucial to increase the capacity of both FIs and farmers. To that end, the third avenue for using climate finance explored here would be crucial.

3. Provide technical assistance to increase investments in agriculture. Public climate finance could play a useful role in helping to strengthen the capacities of the main stakeholders engaged in climate-smart investments, namely lenders and borrowers.

- Lenders

- Build institutional agricultural finance capacities

- Build the capacity of agricultural finance staff

- Customize financial products and services to agriculture

- Borrowers

- Adopt on-farm climate-smart practices and technologies

- Manage risks

- Access finance

Finally, this discussion paper presents several suggestions for achieving the ideas presented, such as:

- Increasing knowledge about innovative and demand-driven financial instruments and mechanisms;

- Bridging information gaps;

- Identifying opportunities;

- Promoting dialogue and cooperation; and

- Designing an action plan to move the agenda forward. 

Chapter 1

\section{AGRICULTURE AND CLIMATE CHANGE}

\section{Key Messages:}

- Agriculture is particularly vulnerable to climate change, and farmers bear some of the most significant risks. However, agriculture is also a major contributor to climate change, and can therefore be part of the climate solution.

- Agriculture features explicitly in the Paris Agreement, INDCs, and SDGs. The Paris Agreement and INDCs have set ambitious goals for mitigation and adaptation that cannot be attained without agriculture playing a major role.

- Agriculture is central to building resilience to climate change. Adaptation- and resilience-oriented agricultural interventions can also yield mitigation and broader development co-benefits, although these cannot be attained if agriculture continues to do business as usual.

- Research and practice have shown that agricultural adaptation and mitigation are technically and economically feasible, and that there are mature and scalable technologies and management methods already available.

- It is crucial to quantify accurately the costs and financial requirements for climate adaptation and mitigation interventions in agriculture and to build up the existing financing, instruments, and mechanisms to support such interventions.

To achieve the UN SDGs, agriculture must be part of the climate solution. By 2030, SDG2: Zero Hunger, aims to "ensure sustainable food production systems and implement resilient agricultural practices that increase productivity and production, [and] that strengthen capacity for adaptation to climate change, extreme weather, drought, flooding, and other disasters." SDG2 specifically calls for doubling the productivity and incomes of small-scale food producers, particularly women farmers and other vulnerable groups. SDG13: Climate Action, has as an objective to "promote mechanisms for raising capacity for effective climate change-related planning and management in least developed countries ... including focusing on women, youth and local and marginalized communities." Similarly, SDG1: No Poverty, aims to "build the resilience of the poor and those in vulnerable situations and reduce their exposure and vulnerability to climate-related extreme events." Given that agriculture is the main source of income for 70 percent of the world's poor (WB 2016), a lowemissions, climate-resilient agricultural sector will be critical to eliminating global hunger and poverty.

\section{Agriculture: Part of the Problem, Part of the Solution}

Progress toward achieving the SDGs will be impeded by the fact that agriculture is extremely vulnerable to climate change. Due to the sensitivity of crops and livestock to temperature, water availability, and extreme weather, climate change threatens agricultural production and therefore heightens the vulnerability of people dependent on agriculture (Lipper et al. 2015). Smallholder farmers-the vast majority of farmers in developing countries-are among the most vulnerable because they have little capacity to adapt, lack safety nets, and are highly exposed to livelihood and food-security risks. The vulnerability of agriculture to climate change also threatens global resilience to climate change more broadly, 
because agricultural production plays a central role in numerous dimensions of food security, such as food availability, the stability of food supplies, access to food, and food utilization (Schmidhuber and Tubiello 2007).

Over the past few decades, a range of technically feasible interventions has been identified to help agriculture adapt to climate change. Most adaptation options build on existing practices in sustainable agriculture (Jarvis et al. 2011); full adaptation to global, climate-related losses in food availability is technically possible (Vermeulen, Campbell, and Ingram 2012). On the farm, a diversified mix of crop and management methods, better use of climate forecasting, management of climate risk, and financial instruments to support these activities can enable successful adaptation. At the global, regional, and national levels, a number of studies have combined models of climate, crop yields, and global trade to estimate and help mitigate climate impacts on incomes and food security. Such modeling is important for evaluating the food security trade-offs of various adaptation options.

Synergies between food security, adaptation, and mitigation have also been found to make agricultural adaptation interventions economically feasible (Vermeulen et al. 2012). Agricultural adaptation avoids the opportunity costs of inaction, and correctly timing investments can maintain productivity growth. Some adaptation options also offer "no-regret" solutions, in that they contribute to food security and resilience without requiring trade-offs for mitigation (Nelson et al. 2012). In fact, broadbased agricultural adaptation has been found to have mitigation co-benefits that are less expensive than many activities designed primarily for mitigation (Lobell et al. 2013). Mixed crop-livestock systems are one type of adaptation practice that has co-benefits for mitigation (FAO 2013).

In addition to being vulnerable to climate change, however, agriculture is also a significant contributor to it. While estimates of agricultural emissions vary, recent data suggest that agriculture accounts for 19 to 29 percent of total anthropogenic GHG emissions (Vermeulen et al. 2012). Moreover, agriculture emits the largest share of any sector of non- $\mathrm{CO}_{2}$ GHGs (54 percent in 2005) and is expected to remain in the lead through 2030 (EPA 2012). Non- $\mathrm{CO}_{2}$ emissions, such as methane and nitrous oxide, have a far greater per-ton warming effect than $\mathrm{CO}_{2}$. Indeed, emissions from agriculture (including forestry) have nearly doubled over the past 50 years, and may increase 30 percent more by 2050 (Tubiello et al. 2014).

Numerous technically feasible mitigation interventions have been identified for agriculture, among them sustainable livestock intensification, changes in rice production, agroforestry, and carbon sequestration. Smith et al. (2007) found that carbon sequestration in cropland, grazing land, and rangeland soils is the greatest potential source of climate change mitigation in agriculture. Primarily due to less deforestation and more carbon sequestration, net GHG emissions due to land use change and deforestation are estimated to have dropped by 10 percent between 2001 and 2010 (Tubiello et al. 2014). This suggests that reducing agriculture-driven deforestation is an important mitigation option for agriculture as well. Because net annual baseline $\mathrm{CO}_{2}$ emissions from agriculture, forestry, and other land use (AFOLU) are projected to decline, these sectors together could become a net $\mathrm{CO}_{2}$ sink before the end of the century (Edenhofer et al. 2014). Finally, done sustainably and efficiently, bioenergy production can be a viable mitigation option (Edenhofer et al. 2014).

It is now much clearer how GHG sources and sinks operate. Because more accurate data are now available on agricultural processes as emitters and on the geographies of agricultural emissions (FAO 2014), it is much easier to identify those mitigation options that can do the most to reduce emissions from agriculture. A recent study by the Climate and Land Use Alliance (CLUA) found that it is possible to reduce annual carbon emissions from global agriculture by as much as 50 to 90 percent by 2030 (Dickie et al. 2014).

Numerous mitigation interventions in agriculture have also been found to be economically feasible. According to a recent OECD review of studies of the cost-effectiveness of mitigation measures in agriculture, a set of often-considered, highly cost-effective mitigation measures and enabling policies is emerging globally (MacLeod et al. 2015). In this context, the IPCC Fifth Assessment Report (AR5) identifies cropland management, grazing land management, and the restoration of organic soils as the most costeffective mitigation options. Finally, many of these options are not only cost-effective, but have adaptation and resilience co-benefits as well.

Given the critical links between agriculture and climate change, as well as the copious evidence that climate change interventions in agriculture are technically and economically feasible, agriculture must 
become part of the climate solution. Indeed agriculture has recently been prominent in UNFCCC and climate finance discussions. However, financing for adaptation and mitigation interventions in agriculture is still minimal.

\section{A Unique Opportunity to Leverage Climate Finance for Agriculture}

Within the UNFCCC negotiations, the COP21 in December 2015 recognized that agriculture is both critically affected by and a significant contributor to climate change. In both the Paris Agreement and the INDCs, ${ }^{1}$ the need for adaptation and mitigation interventions in agriculture is explicit and prominent.

The Paris Agreement explicitly links food production and food security to its objectives. It aims to "strengthen the global response to climate change, in the context of sustainable development and efforts to eradicate poverty" (UNFCCC 2015) and its preamble recognizes "the fundamental priority of safeguarding food security and ending hunger, and the particular vulnerabilities of food production systems to the adverse impacts of climate change." Article 2.1 of the agreement, which sets out the target to limit the rise in global average temperature to well below two degrees Celsius above pre-industrial levels and "pursue efforts" to limit it to 1.5 degrees, emphasizes the need to reduce emissions "in a manner that does not threaten food production" (UNFCCC 2015). The agreement also acknowledges the importance of human rights, gender equality, ecosystem integrity, and biodiversity protection-all issues that are central to agriculture (Meadu et al. 2015).

Crucially, the data demonstrate that it will be impossible to limit the global average temperature rise to the two degrees Celsius mandated by the Paris Agreement without reducing emissions from agriculture (Meadu et al. 2015). With the twodegree target, viable options for reducing emissions from the industrial, transport, and energy sectors will likely run out by 2050 , so that reducing agricultural emissions is imperative (Campbell 2015). Reaching a 1.5-degree target will demand substantially greater mitigation efforts, and thus more urgent agricultural measures (Meadu et al. 2015). Agriculture is also included in the majority of INDCs. All 189 parties that had submitted INDCs by May 2016 (Richards et al. 2016) include mitigation, and 119 of them (about 63 percent) have mitigation
Twenty-nine parties mention climate-smart agriculture (CSA) in their contributions. CSA is a concept that encompasses a set of contextspecific agricultural practices through which productivity is increased sustainably and climate adaptation and mitigation objectives are achieved (Richards et al. 2016).

targets for agriculture. Moreover, 138 parties include adaptation in their INDCs, and 127 of these (about 67 percent) refer to agriculture as an adaptation priority. It appears from an early analysis of INDCs in December 2015 that the parties also recognize the links between mitigation and adaptation, especially in the agriculture and land use sectors, with 44 mentioning the mitigation co-benefits of adaptation actions or vice versa (Richards et al. 2016).

While COP21 outcomes lay a foundation for global action on adaptation and mitigation in agriculture, there is a shortage of finance and other forms of support for the necessary interventions. For example, while the majority of INDCs do mention agriculture, few include specific financing requirements for agricultural adaptation and mitigation interventions. Of the 189 parties that had submitted INDCs by May 2016, only 20 specified the financing requirements for agricultural adaptation (Richards et al. 2016). Most of those parties are African, and only two countries account for over 75 percent of these financing requirements. Only 22 parties specified financial instruments for agricultural adaptation support, such as insurance, credit, and microfinance (Richards et al. 2016). As for mitigation, only 17 parties set out in their INDCs the costs associated with their agricultural and land use mitigation measures and actions. Moreover, many of the cost estimates are conditional, meaning that the country will require international support to cover the costs of mitigation (Richards et al. 2015). Regarding financing mechanisms available to address these issues in agriculture, the INDCs identify only a few, and few parties specify concrete actions for the private sector.

In fact, the funds required for INDC agriculture adaptation and mitigation interventions far surpass the funds that have been pledged for this purpose. An initial analysis of INDCs in December 2015 concluded that considerable additional financing will be necessary to achieve the climate targets for agriculture that less-developed countries have set out 
(Richards et al. 2015). Due to the limited data in country submissions, financial projections based on the INDCs may be underestimated. However, the initial projections already surpass current commitments to climate finance for agriculture, and the annual estimates are significantly higher than the amount multilateral climate funds have spent on agricultural projects in the last decade (Richards et al. 2015). Estimates in the literature also vary considerably; for instance, for the global cost of agricultural adaptation alone, Nelson et al. (2009) estimated US\$7 billion a year up to 2050 and Wheeler and Tiffin (2009) estimated US\$12 billion a year up to 2030 .

With agriculture increasingly being recognized as a major part of the global climate change problem, public funders and private investors have a unique opportunity to close the climate finance gap while making agriculture a part of the climate solution.
With the appropriate tools and financial instruments, investors can increase the small proportion of total climate finance currently flowing to agriculture (CPI 2015) and provide the support necessary for agriculture to both mitigate and adapt to climate change; to achieve that, public finance can act as a catalyst in leveraging private finance. Closing the financing gap will also require dealing with traditional barriers to agricultural finance in general, especially the aspects of those barriers that make it particularly hard to attract climate finance.

\section{Notes}

1. Intended Nationally Determined Contributions (INDCs) become Nationally Determined Contributions (NDCs) once parties to the UNFCCC deposit an "instrument of ratification, acceptance or approval" of the Paris Agreement. 
Chapter 2

\section{FINANCING CLIMATE-SMART INTERVENTIONS IN AGRICULTURE}

\section{Key Messages:}

- Access to sufficient and adequate finance for agriculture traditionally has been, and continues to be, a significant challenge for SMEs and smallholder farmers, in particular women who are disproportionally affected.

- Longer-term investment capital is needed so that smallholder farmers and SMEs can invest and grow their businesses.

- The three main barriers to lending for agriculture are (1) Inadequate enabling environments; (2) lack of capacity to manage exposure to specific agricultural risks; and (3) high transaction costs.

- Climate finance can act as a catalyst to (1) unlock additional sources of finance, specifically private capital; (2) tighten the links between Fls and smallholder farmers and SMEs; and (3) provide technical assistance to build the capacities of everyone involved in the financial ecosystem.

- Additional barriers to the entry of climate finance into the agriculture space are, among others, (1) difficulty in demonstrating short-term "quick wins;" (2) limited capacity to assess adequately what is needed to finance adaptation and mitigation; (3) the fragmentation of climate finance sources; (4) broken links between financiers and farmers; and (5) lack of capacity and readiness at the country level.

\section{Traditional Constraints on Financing for Agriculture}

Accessing sufficient and adequate financing for agriculture has been difficult in developing countries for decades. Traditionally, a much smaller share of the financial sector loan portfolio has gone to agriculture than to other sectors, especially compared to agriculture's share in GDP. Due to perceptions of its low profitability, low margins for financiers, high actual and perceived risks, and high transaction costs, (among others) financiers in most countries limit their exposure to agriculture, raise interest rates, tighten lending criteria, shorten terms, require other lending conditions, and often avoid lending to agriculture, seeking more stable returns from such sectors as trade, housing, and energy. The resulting financing shortfall severely impacts the agriculture sector, both farmers and SME agribusinesses.

In this discussion paper, agricultural finance ${ }^{1}$ refers to the provision of financial services to smallholder farmers and SMEs engaged in activities related to agriculture. It encompasses a vast range of lenders, borrowers, and services. Among those engaged in financing agriculture are banks, nonbank FIs, microfinance institutions, value chain actors (which have a major role in agricultural finance), aggregators, and social lenders. Among recipients are smallholder farmers, collectors, traders, and processors and other agricultural SMEs. While this discussion paper pays special attention to the first, financial services may also include:

- Lending, short-term for working capital loans and longer-term for investment capital loans;

- Equity capital;

- Leasing;

- Mobilization of Savings and Deposits; and

- Financial intermediation, such as mobile financial services, transfers, payments, and insurance. 
Smallholder farmers find it hard to access finance. They generally have little financial literacy, scant or no collateral, few alternative and supplemental sources of income, and little or no credit history and track record of successfully repaying loans. Lenders, too, find it difficult to reach them because smallholders are often highly disaggregated and scattered across remote areas far away from lending institutions. The resultant high transaction costs for the lender are rarely outweighed by the small loan amounts that farmers require. Due to socioeconomic, political, and legal barriers (WB 2014a), accessing finance is an even more acute problem for women: in developing countries, only 50 percent of women have access to a bank account compared to 59 percent of men. Some of the barriers are related to the difficulties women have in proving their identity, building financial history, and proving creditworthiness, as well as their lack of land ownership and reduced physical access to financial services.

Moreover, even where smallholder farmers have access to formal financial services, the lending methodologies and portfolio of financial products and services on offer are often not designed to meet their financial needs and cash flows. For instance, FIs tend to mostly offer short-term working capital rather than longer-term investment, which limits the ability of smallholder farmers to invest in those productive activities and equipment that can generate more added value and increase productivity. Moreover, financiers often offer fixed repayment schedules and short maturities that, because agricultural production cycles are seasonal, are not adapted to smallholder cash flows. Moreover, the portfolio of financial products is often standardized rather than customized to the specific needs of the clients; thus products and terms are often not demand-based, which sometimes leads to poor market uptake.

Because the vast majority of farmers in developing countries are smallholders and women, the absence of suitable financial products remains a major obstacle to the development of agriculture; the continuing disenfranchisement of women and other smallholder farmers from the financial system also keeps them from opportunities for economic growth. The Initiative for Smallholder Finance estimates that total smallholder financing demand in Latin America, Sub-Saharan Africa, and South and South East $\mathrm{Asia}^{2}$ is estimated at US\$210 billion (Dalberg 2014). Moreover, the financing gap is likely to widen substantially with the heightened need for longer-term loans to fund adaptation and mitigation activities.
Agricultural SMEs also find it difficult to access financing, especially the longer-term loans they need to invest in order to grow their businesses. SMEs are critical for agricultural development because their activities help to increase smallholder incomes, improve productivity, and add to the efficiency of value chains, thereby generating rural jobs. When SMEs lack the financing they need to grow to their full potential, they generate fewer jobs. With rural unemployment already a major challenge in developing countries, the financing gap for agricultural SMEs is thus exacerbating rural poverty across the globe.

While longer-term loans for investment are crucial for SMEs to grow, they are much less accessible than short-term working capital loans. SMEs require loans too large to be met by microfinance but not large enough-and perceived as too risky-to be met by commercial FIs. This longer-term finance gap, the "missing middle," results from the mismatch between the tenures of deposits and of mediumterm loans, and from the fact that longer-term loans often are much riskier for lenders. It is especially problematic when producers and enterprises wish to invest in value-adding infrastructure that could significantly raise their productivity and incomes but are trapped in a lower-value equilibrium due to the lack of medium- and long-term finance.

Development agencies and both public and private sector actors have made multiple interventions to overcome the agricultural financing gap. The results have been mixed. The interventions have often involved directed credits, mandated lending by banks to agriculture, technical assistance for both borrowers and lenders, and the provision of credit lines and risk- sharing instruments, such as partial guarantees. However, financiers often lack incentives to prioritize customer centricity and tend to use standard interventions that do not get past the specific finance barriers in agriculture or meet the needs of specific groups. For example, a short-term loan with monthly repayments may be offered to a farmer whose income is seasonal and who needs a longer maturity and a repayment schedule aligned with seasonal cash flows.

\section{The Main Barriers to Lending to Agriculture}

While the difficulties of closing the financing gap for agriculture are numerous, this section discusses three of the most common barriers: an inadequate enabling environment, exposure to specific 
Figure 2.1. Key Barriers to Lending

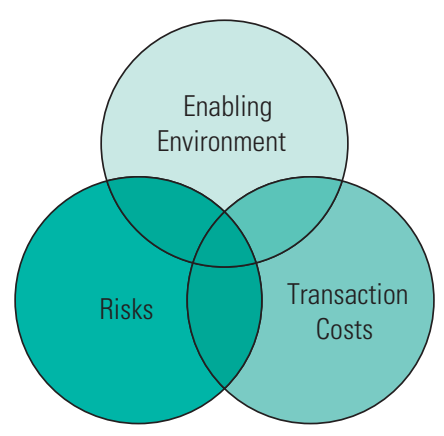

agricultural risks, and high transaction costs. These three barriers (Figure 2.1), which most limit the ability of financiers to lend to farmers and SMEs, are closely related and thus affect each other.

\section{Inadequate Enabling Environment}

A lack of effective policies and regulations governing agricultural finance not only discourages lending but also creates additional barriers to the flow of liquidity to agriculture. How governments support development of agriculture has a clear impact on how agricultural and financial markets operate. In some cases, governments fail to recognize the economic and market potential of agriculture, inject subsidies that distort the financial environment, discourage the development of private sector solutions, and create additional barriers to financing for agriculture. Quite common practices are mandatory lending quotas, highly concessional lending de-linked from the market, loan rescheduling and forgiveness, interest rate subsidies and ceilings, highly subsidized insurance, limitations on product development (warehouse receipts, leasing), savings mobilization, and contract enforcement.

Moreover, a lack of effective policies and regulations can also affect sectors that, while not related directly to agricultural financing, are essential to its development, such as infrastructure and telecommunications. A lack of policy support for these sectors may perpetuate some of the challenges that agriculture faces, such as high transaction costs and information gaps.

\section{Lack of Capacity to Manage Specific Agricultural Risks}

The complexities of agriculture require that both farmers and financiers simultaneously understand, assess, accurately estimate, and manage specific and multifaceted agricultural risks. For instance, one of the most common characteristics of the agricultural sector in developing countries is the inability of both farmers and financiers to fully manage the impacts of the risks related to the seasonality of agricultural cash flows, which has severe effects on both the financial management capacity of farmers and the quantity and quality of the products financiers offer them.

On the one hand, the revenues smallholder farmers and agricultural SMEs generate often depend on seasonal production cycles. The resulting variability in income and liquidity over the course of a year can make it difficult for them to manage their finances, which in turn limits their capacity to invest in productive activities and save capital to invest in equipment or access other financial services. On the other hand, irregular cash flows are also risky for financiers, particularly if their investments are spread over long periods of time and are to be repaid in lumpsum installments over several seasons. This investment structure can reduce the amount of deposits available for lending, making loan management and monitoring more difficult and costly and requiring additional capital to design products tailored to the agricultural situation.

Moreover, farmers and agricultural SMEs are often ill-equipped to manage the specific risks of the agriculture sector. They often lack the knowledge and capacity to recognize and manage those risks and diversify their activities accordingly. In many cases, they either focus exclusively on one agricultural activity or have a portfolio of activities that is only apparently diversified because all the activities are exposed to similar risks. They also often lack the skills and necessary resources to improve their agricultural practices and technologies, buy higher-quality inputs, and (where available) acquire insurance to help them better manage their exposure and reduce its negative impact on their production, incomes, and thus repayment capacity. Among risks specific to agriculture are (WB 2014b):

- Production risk: the variability in agricultural output due to external and internal factors. The main external factors are climatic risks (drought, rainfall, changes in temperature, etc.) and the risks of pests and diseases. Internal factors are those intrinsic risks derived from inadequate farm management practices, such as lack of adequate farming skills and use of poor-quality inputs. 
These risks are significantly higher for farmers and SMEs that concentrate production in single crops that are sensitive to specific inputs, climates, and harvest timing.

- Marketing risk: the inability to sell on time, in the right quantities, or to an acceptable quality standard. This is highly influenced by the absence of marketing contracts and the short-term and longterm market situation, which severely increases exposure to this type of risk. Furthermore, the lack of sufficient finance and adequate inputs to produce the right quantity and quality exacerbates the exposure.

- Price risk: the likelihood of financial losses due to changes in the level or volatility of commodity prices. Often in agricultural markets there are significant information asymmetries and a lack of good communications infrastructure. The prices that outputs will sell for in the market are unknown for farmers at the time of planting, and these vary according to the supply and demand at the time of sale. Often, too, farmers and SMEs lack facilities for storing non-perishable products to sell when prices are more favorable, and are unable to access future and forward contracts and hedging options.

Financiers are also often ill-equipped to understand or manage the risks specific to agriculture. Because they often do not have the technical knowledge necessary to understand the economics of farming and how agricultural markets work, many lenders fail to undertake detailed diagnostics to identify the specific risks associated with agriculture, which leads to their perception that this is a high-risk sector. Moreover, they often are unfamiliar with the structured risk management approaches and skills they need to accurately calculate and manage those risks and to assess the capacity of farmers to reduce them. Coupled with the often-insufficient risk management capacity of farmers, the result is that financiers lend only to those clients they believe have a lower credit-risk profile.

As a way to manage risk, therefore, financiers often request collateral from smallholder farmers and SMEs, who often have little or no collateral, either because they do not own land or other valuable assets, or because they live in areas where land property rights are not recognized or land titles are not registered. Even when farmers have assets, they are often of low monetary value or unsuitable to meet financing requirements, in which case, FIs may impose restrictive lending conditions.
Figure 2.2. Risk Profiles along the Agricultural Value
Chain

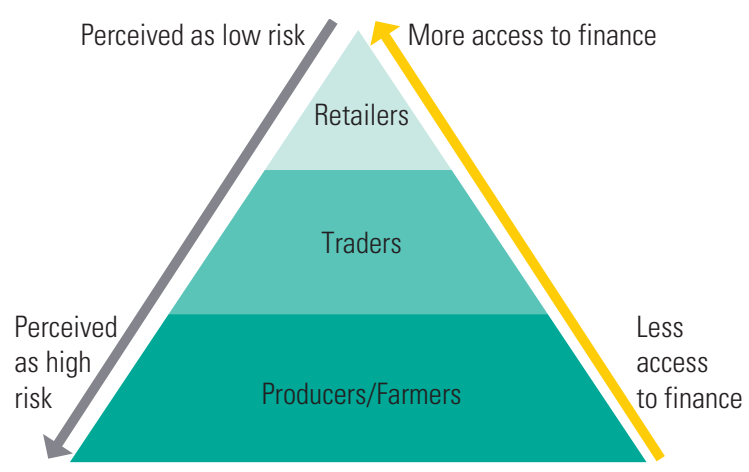

The risk profile of the borrower and the purpose of borrowing significantly influence how much financing is available (Figure 2.2). Smallholders are usually less able to access finance than are SMEs; generally, the further up the agricultural value chain a potential borrower is, the easier it is to access finance, because SMEs that are aggregated and integrated in value chains are better-placed to meet the lending criteria of financiers.

\section{High Transaction Costs}

High transaction costs pose a substantial barrier to lending to farmers. Compared to borrowers located in densely populated urban areas, farmers and agricultural SMEs tend to be located far from FIs, which often can be accessed only via poor roads and related inadequate physical infrastructure, such as electricity and communications. Moreover, the low population densities of rural areas mean that reaching those farmers that are disaggregated and thus not integrated into value chains is significantly more difficult, and therefore more expensive.

To reach the market segment made up of smallholders and agricultural SMEs, many financiers would need to make substantial investments in expanding branch networks, recruiting and training new staff, and building systems to promote, process, supervise, and collect on loans. These transaction costs generally reduce the profit margins that financiers can make only by administering a large number of relatively small loans, which discourages them from lending to farmers. Reducing some of the transaction costs may require new financial service delivery channels that use information and communication technologies (ICTs) and innovative partnerships and business models so that they can expand 
Box 2.1. From Financing Agriculture to Financing Climate-smart Investments in Agriculture

Building climate-smart food production systems will require additional capital, particularly from public sources, and customized financial products (FAO 2012). In particular, climate-smart investments in agriculture tend to require substantial upfront investments to support the transformational changes necessary to heighten farmers' productivity and their capacity to adapt to climate change while reducing the emission intensity of what they produce. This requires not only a significant increase in the amount of capital available but also longer maturities (5-7 years) and more flexible conditions (repayment schedules adjusted to cash flows) so that farmers can make the necessary investments to maintain or increase current yields, produce more food on less land, and adopt climatesmart practices and technologies to increase their resilience while also reducing emissions.

their networks and significantly lower the costs of transactions compared to those of the traditional "bricks and mortar" approach.

Leveraging additional finance for climate-smart investments in agriculture requires consideration of how to address specific barriers. However, with the appropriate tools and financial instruments, financiers would be able to increase the proportion of climate finance flowing from public and private sources to agriculture and provide the support necessary for agriculture to both mitigate and adapt to climate change.

\section{How Climate Finance Relates to Agricultural Finance}

All development finance today is provided in a world shaped by climate change, which jeopardizes the achievement of core development goals and most impacts poor people and the underprivileged; finance of all types will be critical to support the transition to low-carbon, resilient economies in all sectors. Ultimately, the increased use of public climate finance has the potential to unlock additional finance, particularly from private sources; it can also support structuring the enabling environments needed to support healthy public and private sectors and increase the flow of agricultural finance directed to farmers to expand the domestic revenue base. All sources of financing are needed to make this transition a success.
Box 2.2. "Climate Finance" in this Paper

In this discussion paper, climate finance refers to the flows of capital from both public and private sources that support and finance climate-smart investments and aim to achieve climate change adaptation and mitigation objectives. Climate finance is considered to be a source of capital for climate-smart investments that has demonstrated its ability to unlock additional public and private capital from a variety of sources, including domestic national budgets, the private sector, bilateral and multilateral actors, DFls, and institutional investors.

Within the ecosystem of finance, sources that are categorized as "climate finance" can be critical to:

- Unlocking additional sources of public and private capital to finance or co-finance both public and private goods, not only through project development but also by establishing financial aggregation models, among other options, to further climate-smart investments in agriculture.

- Strengthening the links between FIs and farmers to effectively channel sufficient flows of capital to both smallholder farmers and SMEs.

- Supporting and paying for the necessary-and critical-technical assistance to increase the capacity of the financial ecosystem, including financiers, smallholder farmers and SMEs, and other agriculture actors.

\section{Scope of Climate Finance}

While climate finance has evolved over the years, there is as yet no unique definition (but see Box 2.2). In the broader sense, climate finance refers to all financial flows, regardless of origin, that help to achieve climate change adaptation and mitigation objectives. The Climate Policy Initiative (CPI), the Organisation for Economic Co-operation and Development (OECD), the multilateral development banks (MDBs), and other institutions track parts of these financial flows annually. Tracking annual financial flows that support climate objectives helps policy makers, investors, and other actors to better understand the total amount of actual investments and climate finance committed globally and also provides a context for the estimates of additional investment needed to meet mitigation and adaptation objectives. 
This discussion paper explores the importance of public and private sources of climate finance in unlocking, catalyzing, and accelerating climate-smart investments in agriculture. It therefore gives priority to the ability of climate finance, specifically public climate finance, to unlock additional sources of capital, especially private, throughout the entire climate finance ecosystem to accelerate climate-smart investments that can help smallholder farmers and SMEs meet adaptation and mitigation objectives.

The annual reporting by CPI on all climate finance is one of the most comprehensive reporting mechanisms to date. Included in the CPI publication Landscape of Climate Finance are both funds originating from public sources and the investments of a wide range of private financial actors. While CPI does not claim to capture all financial flows supporting climate-smart investments, it does draw on data from a variety of sources, including OECD/DAC, the MDBs, the International Development Finance Club, and private finance for energy investments as captured by Bloomberg New Energy Finance. CPI defines climate finance as "the financial resources paid to cover the costs of transitioning to a low- or zero-emissions global economy and to adapt to, or build resilience against, current and future climate change impacts" (Falconer and Stadelmann 2014).

\section{Sources and Intermediaries}

This category is perhaps the most important for understanding how and where financing that supports climate action originates, because it covers sources of capital from the following:

- Government budgets (public capital);

- Public financial intermediaries, such as bilateral aid agencies, climate funds, and multilateral, bilateral, and national development finance institutions (DFIs) ${ }^{3}$

- Private financial intermediaries, such as commercial FIs, private equity, venture capital, infrastructure funds, and institutional investors; and

- Households, private national and multinational companies, and project developers (private capital).

\section{Instruments}

There are several financial instruments that emanate from intermediaries and sources of climate finance, among them grants, low-cost project debt ("concessional" loans), market-rate debt, project equity, private equity funds and other aggregation vehicles, balance sheet financing, and risk mitigation instruments, such as guarantees and insurance.

\section{Recipients}

Recipients of climate finance fall into several general categories:

- Public recipients;

- Private recipients;

- Private NGOs and foundations;

- Public-private recipients, primarily public-private partnerships (PPPs); and

- Unknown sources.

\section{Uses}

Climate finance is usually directed to those uses that achieve mitigation objectives and adaptation objectives and those that meet multiple climate objectives. CPI tracks total investments in projects, not simply the incremental costs of making a project meet mitigation or adaptation investment objectives. It does not track revenue support mechanisms, such as revenue from carbon credits or feed-in tariff mechanisms. This helps ensure that financing counted as climate investments are actual investments, not hypothetical calculations about incremental investments over carbon alternatives.

Traditionally, international climate agreements have a primary focus on public sources of finance that support climate-smart investments. In this context, climate finance consists of those funds primarily provided by governments to meet climate change mitigation and adaptation objectives that are channeled through national, bilateral, regional, and multilateral international entities, such as bilateral aid agencies, and national, regional and multilateral DFIs, among others. It also includes climate-specific funds, such as the Green Climate Fund (GCF), Climate Investment Funds (CIFs), the Global Environment Facility (GEF), and bilateral climate funds that finance mitigation and adaptation investments, including the technical assistance and capacity building needed to facilitate and encourage the transition to a low-carbon, climate-resilient path for developing countries. 


\section{Overview of Climate Finance Architecture}

The relationship between the "climate finance architecture," the channels of public sources of climate finance, and its ability to unlock private sources of capital is critical, because those public sources are best able to catalyze and crowd-in sources of private capital. Understanding the landscape of climate finance in general, and the specific role of its public sources, can provide critical insights into how to make finance more effective in achieving climate objectives along the entire agricultural value chain.

Currently, the financial architecture behind public climate finance flows is multifaceted. Within it, it is important to put the spotlight on the important role of the dedicated climate finance funds that have been established as vehicles for donor funding to finance mitigation and adaptation investments. Among those that support climate-smart investments in agriculture are:

- Green Climate Fund;

- Global Environment Facility (GEF);

- Least Developed Countries Fund (LDCF - GEF);

- Special Climate Change Fund (SCCF - GEF);

- Pilot Program for Climate Resilience (PPCR - CIF);

- Adaptation Fund (AF);

- Bio-carbon Fund; and

- Amazon Fund.

Public sources of climate finance (US $\$ 148$ billion in 2014) make up a small portion of the total more general financing (US $\$ 391$ billion in 2014) that works to forward climate objectives each year (CPI 2015). These funds also have an important role in unlocking additional sources of private capital, including financing from project developers, commercial FIs, private equity, and (sometimes) institutional investors.

An important characteristic of these public sources is that they can offer more attractive terms than the markets. Many bilateral and multilateral channels, and almost all specific climate funds, deploy this financing into public and private investments in the form of both grants and market-linked financing instruments. The ability to price below the market gives these funds a particularly catalytic role in financing projects by filling the gap that the markets cannot or will not finance due to risks, real or perceived. This approach has come to be known as "blended finance." Used in a targeted and disciplined manner, it is considered an effective way to deliver subsidies without crowding out other sources of financing or unnecessarily distorting markets. While such funds are considered concessional, the pricing of financing with respect to private sector operations in particular is meant to minimize the subsidy element to just what is needed to make the investment happen.

\section{Blended Finance}

The term "blended finance" has emerged over the last few years as donors and philanthropies have recognized the increasing need to attract private capital to address development objectives. Blended finance specifically refers to the ability to use scarce public resources structured through grants, low-cost debt, guarantees, and (patient) equity both at the project and vehicle level in emerging markets to crowd in private capital. Blended finance occurs in most sectors important for achieving climate change objectives, among them energy, infrastructure, and agriculture. For example, the Global Agriculture and Food Security Program (GAFSP; Box 2.3) is a donor-funded mechanism created to scale up investments in agriculture by blending public sources of capital with MDB ownaccount financing and to crowd-in private investment.

Blending public sources to crowd in private investment is particularly useful when:

- The perceived risks in the market are higher than the actual risks, and enticing private investment to meet development objectives proves or demonstrates the business case for commercially viable activities; and

- Significant development impacts can be gained, but perhaps over a longer time horizon than investors are typically used to; in these cases, structuring public sources can help crowd-in the necessary private investment.

Blended finance has also been widely used in aggregation vehicles with local FIs and fund-offund structures, and in the impact-investing space to crowd in private capital for projects that might otherwise have been too small for direct investment. Public funding blended into these aggregation vehicles makes it possible for risks to be shared with donors, allows for a portfolio approach to managing risks, and can attract private investors. 


\section{Box 2.3. The Global Agriculture and Food Security Program (GAFSP)}

GAFSP supports critical medium- and long-term interventions needed to ensure strong and stable policies and more investment in agriculture, and to make transformative impact on rural incomes and food and nutrition security in the world's poorest countries. Implicit in these goals is the program's concerted effort ${ }^{a}$ to increase climate resilience and offset any negative effects on or from climate change, to which the poorest countries are the most vulnerable.

GAFSP works through complementary public and private sector investments:

- The Public Sector Window provides grant financing for strategic, country-owned, and country-led programs in low-income countries that have prioritized agricultural development and put in place a sound policy framework.

- The Private Sector Window provides a range of blended finance solutions (loans, guarantees, and equity) to support early-stage private-sector activities in agriculture that may not attract commercial funding due to perceived high risks.

Through both windows, GAFSP aims to attract private investment and provide innovative financing solutions across the entire food supply chain in order to increase production and incomes for those living and working in the world's lowest-income countries. Through experience, GAFSP has demonstrated how to leverage both public and private resources: for all Public Sector Window projects now underway, 60 percent of financing is from GAFSP and 40 percent from other sources; for the Private Sector Window, the leveraging ratio of GAFSP resources and other private funds is 1:7. Through its complementary windows, GAFSP has been able to demonstrate, on the ground, the development impacts that can be achieved when public and private financing work together.

${ }^{a}$ Twenty-three GAFSP Public Sector Window projects and 45 percent of funds, contribute to climate change co-benefits through various climate-smart activities.

\section{Role of Climate Finance in Agriculture}

Climate finance can play a critical role in directing liquidity to agriculture. Agricultural investments that address mitigation and adaptation goals are eligible for public sources of climate finance. The sources are mainly national, bilateral, and multilateral sources, DFIs, and dedicated climate funds, such as the GEF, the CIFs, specifically the Pilot Program for Climate Resilience (PPCR-CIF), and the new Green Climate Fund (GCF). These sources of public climate finance are essential to heighten climate-smart investments in agriculture and support the transition to low-carbon and climate- resilient economies.

For instance, the World Bank Group has committed to increase the climate share of its portfolio from 21 to 28 percent by 2020 , when it should reach total financing, including leveraged co-financing, of about $\$ 29$ billion a year. In particular, the WB has committed to 100 percent of its agriculture operations being climate-smart by 2019; to date 42 percent of the Agriculture Global Practice pipeline projects are already delivering climate-smart investments.

However, in light of climate change, these resources must be used efficiently because increasing the amount of public climate finance available may not be sufficient to build more climate-smart food systems. It is essential to clearly understand the risks that climate change poses to the agriculture sector and its financing, as well as the risks and effectiveness of potential mitigation measures, so that decisionmaking incorporates climate risk considerations to help address, where possible, how investments can be risk-proofed. To this effect, it is critical to ensure that a structured and systematic approach is used to undertake due diligence and flag potential climate risks, both short- and long-term, and help ensure that these are properly assessed and managed to help mainstream climate resilience into policies and investments. In this regard, climate finance must play a catalytic role in providing the resources and building the necessary capacities to facilitate this process.

When public climate finance is used effectively through a balance of risk mitigation and other market-linked instruments that help rebalance the riskreward profiles of highly impactful demonstration investments, financial instruments can be used to leverage and catalyze private finance in agriculture. Climate finance can be tailored to meet the risk profiles of all types of investors interested in realizing climate-smart investments, from those looking to increase direct access to finance for smallholders and SMEs to those interested in more complex value chain finance, trade, and commodity financing and aggregation vehicles that offer more attractive structures for large-scale impact and institutional investors.

Climate finance can also be critical in reducing risk perceptions and crowding in private capital. 
Potential functions of climate finance in investments in agriculture are two-fold:

- Climate finance can fill a financing gap and catalyze investment that would not otherwise happen unless there are risk mitigation/risk-sharing instruments or softer terms or subordinated positions that allow for investment of private capital; and

- It also offers an opportunity to prove its viability to private investors and commercial lenders who are unwilling to expand their lending in agriculture.

The second function is perhaps more critical to scaling up liquidity at all levels of the agriculture financing value chain and could help to dismantle some of the more entrenched barriers for financial markets and actors to expand into agriculture at scale.

Climate finance has in the past been deployed to support agricultural projects through the following basic instruments:

- Grants;

- Loans, both concessional and not concessional and in senior and subordinated positions;

- Guarantees and other risk-sharing mechanisms;

- Equity, often more patient or willing to cap returns, at the project and the vehicle level; and

- Performance-based mechanisms

The selection of specific climate finance instruments depends on several factors, including:

- Which market barrier is being addressed;

- Which segment of the market is being addressed;

- Who the counterparties in the investment are;

- The limits of other sources of private capital in that market; and

- Total market liquidity.

\section{Barriers Preventing Climate Finance from Flowing into Agriculture}

It is estimated that only a small portion of total climate finance flows into agriculture.

- The total amount of climate finance invested globally in 2014 was an estimated US $\$ 391$ billion, from both public ( 38 percent) and private (62 percent) sources.
- Of total climate finance flows, 93 percent was allocated for mitigation, 6 percent for adaptation, and 1 percent for combination activities.

- Of the $\$ 391$ billion total, only $\$ 6-8$ billion was invested in agriculture, forestry, and other land use. About $\$ 3$ billion was directed to adaptation and another $\$ 3$ billion to mitigation (CPI 2015).

In addition to the most common barriers to lending to the agriculture sector-inadequate enabling environments, exposure to risks, and high transaction costs-a variety of other factors also constrains access to sufficient climate finance to enable scaling up climate-smart investments in agriculture in most developing countries:

- Insufficient awareness of the vulnerability and the contribution of agriculture to climate change has traditionally directed the attention of climate finance to other sectors. Further, the lack of economies of scale, due to the small-scale composition of the farming sector, has made it hard for agriculture to demonstrate its potential to achieve positive climate outcomes at scale. As a result, most climate finance resources have been directed to sectors that can quantifiably demonstrate positive impact and significant reduction of GHG emissions in the short term.

- The agriculture sector has limited capacity to identify its financial needs for adaptation and mitigation purposes. Moreover, lack of agreement on the very definitions of adaptation and mitigation in agriculture and insufficient technical and financial capacity to screen for climate risks and build climate-smart agriculture profiles, much less the necessary cost-benefit analysis and investment plans, have limited the ability of governments and other stakeholders to quantify and mobilize the investments needed to make agriculture more climate-smart.

- Climate finance resources are fragmented (Salmes et al. 2012). Traditionally, most of the climate finance available (93 percent in 2014) has been directed to mitigation purposes, specifically the energy sector, because it can reduce GHG emissions and demonstrate "quick wins" in the short term (CPI 2015). However, donors and funds like the Green Climate Fund are increasingly recognizing both the vulnerability to and the contribution of agriculture to climate change and acknowledging the importance of allocating resources 
to climate change adaptation in agriculture by explicitly incorporating it into their mandates (GCF 2015). Nonetheless, far more resources are needed to appropriately fund climate-smart interventions, which require a holistic approach that promotes productivity, adapting to climate change, and reducing emissions.

- The links between financiers and smallholder farmers and SMEs often do not work effectively and at scale. Current channels to deliver finance to the agriculture sector often do not directly reach farmers, who are ultimately responsible for doing what needs to be done to adapt and mitigate the effects of climate change. This is increasingly challenging when climate-smart interventions require upfront investments or additional capital. Hence, it is critical to improve the current climatefinancing architecture and to open more efficient, innovative, and transparent channels to facilitate the flow of finance directly to farmers, so they can access the necessary resources to invest in climatesmart interventions and thus increase their capacity for resilience and mitigation.

- Countries often do not have the capacity to access all the climate finance they need. Another problem for investors is often the lack of a robust and attractive pipeline of climate-smart investments in agriculture. Quite often this is closely related to the lack of capacity in recipient countries to conduct environmental and socioeconomic studies, address climate change constraints, and design technical projects that deliver climate- smart outcomes while meeting all the requirements for accessing climate finance. More technical and financial support is needed to build the capacity and readiness of countries to address climate-change constraints and build a robust and sustainable pipeline of projects that can attract further investment.
- The evidence base for the most suitable climatesmart interventions is insufficient (FAO 2013). Because climate-smart investments in agriculture are context-specific, adaptation and mitigation interventions need to be tailored to the particular local context. However, more research is needed to clearly identify the climate-smart interventions that would be most suitable for specific contexts and their adaptation and mitigation potential. Research is also needed to produce technological innovations that can accelerate the scaling-up of climate-smart investments in agriculture (FAO 2014).

- Currently, metrics and tools are not adequate to accurately measure the impact of climate-smart interventions. Agriculture has traditionally faced significant constraints on assessing the potential impact of adaptation and mitigation activities due to the lack of internationally recognized metrics and monitoring and evaluation tools that can measure the exact impact of such interventions. Therefore, more research is needed to identify accurate ways to measure climate outcomes at the farmer and firm level. Metrics that are not adequate and overly complex impact measurement methodologies and tools also discourage private investments in agriculture.

\section{Notes}

1. A significant amount of finance flows to agriculture in the form of public subsidies (direct grants from the government), but this issue is not addressed in this discussion paper.

2. This figure excludes China, Central Asia, and the Middle East and North Africa.

3. CPI considers government sources of capital and public FIs to be two distinct sources of capital, although many governments channel their capital through public FIs. 
Chapter 3

\section{LEVERAGING CLIMATE FINANCE TO MAKE AGRICULTURE PART OF THE SOLUTION}

\section{Key Messages:}

- Climate finance can address the financing gap in the agriculture sector by channeling additional sources of finance that deliver positive climate outcomes directly to smallholder farmers and SMEs.

- It can also function as a catalyst for the design and adoption of innovative mechanisms to leverage additional sources of capital, specifically from private sources.

- Such mechanisms might include (1) PPPs to leverage not only resources but also expertise and capacities; (2) investment vehicles that can help attract additional capital by diversifying, managing, and rebalancing risk-return profiles; and (3) bundling a wide range of financial instruments to make the use of capital more effective.

- Entry points that can help direct public climate finance into agriculture and link financial institutions to smallholder farmers and SMEs are (1) improving the enabling environment; (2) supporting Fls to build up their risk management mechanisms; and (3) supporting Fls to reduce transaction costs.

- For each entry point, there are a number of interventions that could be undertaken to achieve the objectives of that specific entry point. For each potential intervention, there is a list of suggested initiatives that could be funded with climate finance.

- If the suggested interventions and mechanisms are to function effectively, it is imperative that climate finance provides technical assistance to both financiers and smallholder farmers and SMEs so that both parties can build the capacities they need to use the resources available effectively.
As is already clear, the substantial financing gap in the agriculture sector can only widen given the additional capital needed to help developing countries tackle the challenges that climate change poses to the agricultural sector. It is therefore essential to increase the flow of finance to farmers so they can better adapt to climate change and reduce the emissions intensity of agricultural production. Climate finance is critical to addressing this financing gap by providing new and better-targeted sources of finance and directing them (either directly or through intermediaries or aggregation structures and vehicles) to those smallholder farmers and SMEs that can achieve positive climate outcomes.

If climate finance is to effectively address this financing gap, barriers to lending for agriculture will have to be dismantled. The current links between FIs and smallholder farmers and SMEs do not always work properly, in particular at scale, and financial resources are not reaching those farmers and SMEs that will need to adapt and mitigate the adverse effects of climate change. It is therefore essential to first create the conditions that will allow climate finance to flow to farmers and SMEs directly.

To this end, climate finance could be used to reinforce the links between FIs on the one hand and smallholder farmers and SME agribusinesses on the other. For instance, climate finance resources might be used to develop or improve the agricultural finance enabling environment, such as policies and regulations necessary to mobilize and channel financial flows to farmers. They could also be used to support FIs to better manage risks and incentivize them to increase lending to farmers and SMEs, to develop new financial delivery channels, and to design financial 
instruments and structures tailored to suit the needs of smallholder farmers and SME agribusinesses.

This would be a win-win for climate finance, because such resources could help bring about positive climate outcomes while also generating significant financial and social returns. To achieve this, public and private sources of climate finance will need to adopt innovative ways to attract additional capital to the agricultural sector. Specifically, these sources will need to:

- Use partnerships and innovative investment vehicles to bring in additional finance for climate-smart interventions in agriculture, such as using concessional public resources to reduce risk and help rebalance the risk-reward profiles of investments;

- Identify the best entry points for directing climate finance into agriculture and for linking FIs directly to smallholders and agricultural SMEs; and

- Build the necessary capacity to maximize these sources of climate finance.

\section{Innovative Ways to Attract Additional Capital to Agriculture}

\section{Public-Private Partnerships}

Partnerships, particularly PPPs, can help catalyze additional capital from both public and private sources. PPPs in particular tend to have a multiplier effect by leveraging diverse types of expertise, skills, resources (technical and financial), and networks (Figure 3.1). More importantly, they can help to accommodate the interests of a wide range of actors with different risk appetites, desired investment returns, and social, economic, and environmental goals. Partners in PPPs may be:

- Public donors;

- International and nongovernmental organizations (NGOs);

- Foundations;

- Research institutions;

- UN organizations;

- Development FIs;

- IFIs;

- Private companies; and

- Impact or institutional investors.

\section{Innovative Investment Vehicles}

Well-designed layered capital structures are often essential for leveraging additional capital while meeting the different expectations of each potential investor. Such structures not only increase the amount of capital available but also diversify risk and investment returns, and add flexibility to the terms (maturity) and uses of the capital. PPPs that

Figure 3.1. Multiplier Effect of PPPs

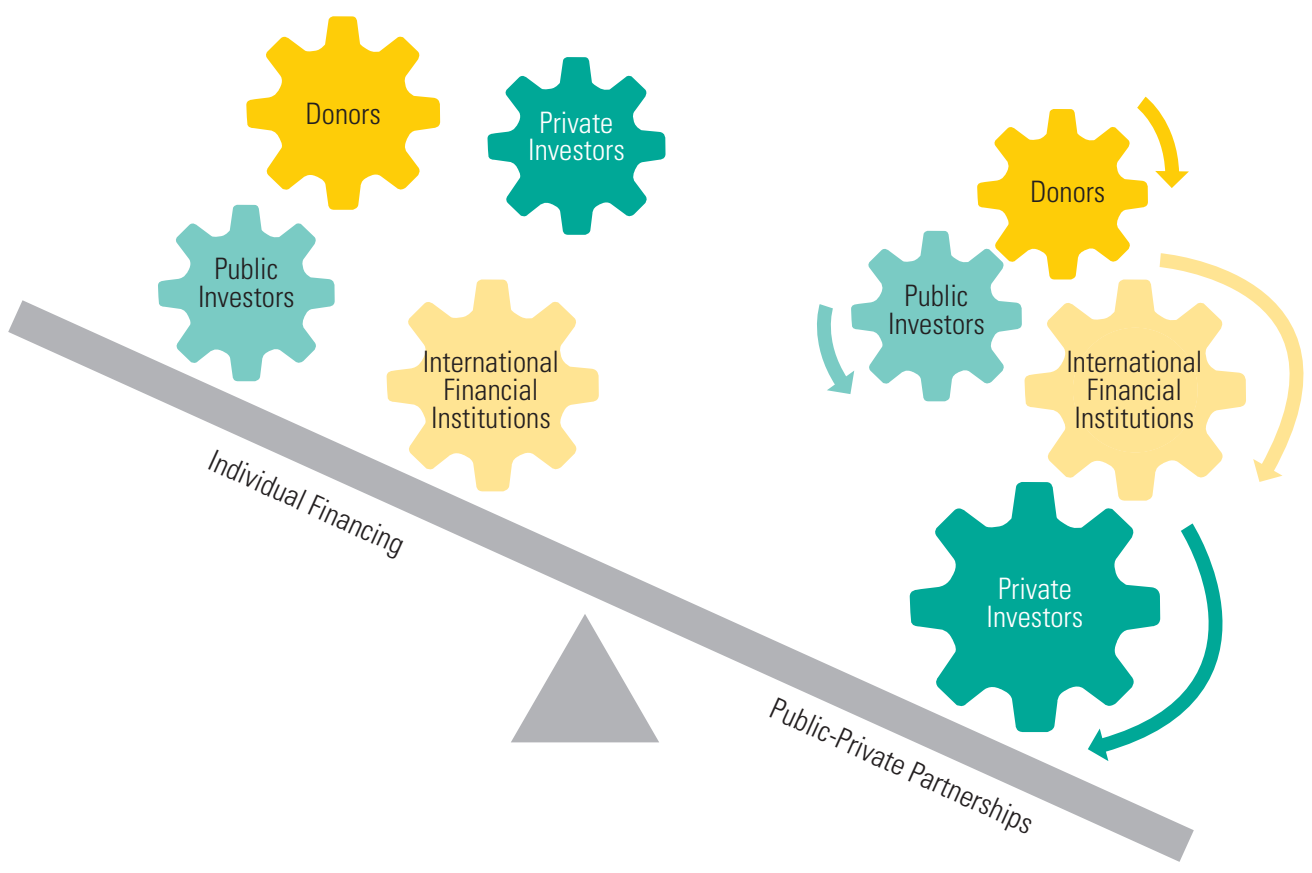


Figure 3.2. Examples of Layered Capital Structures

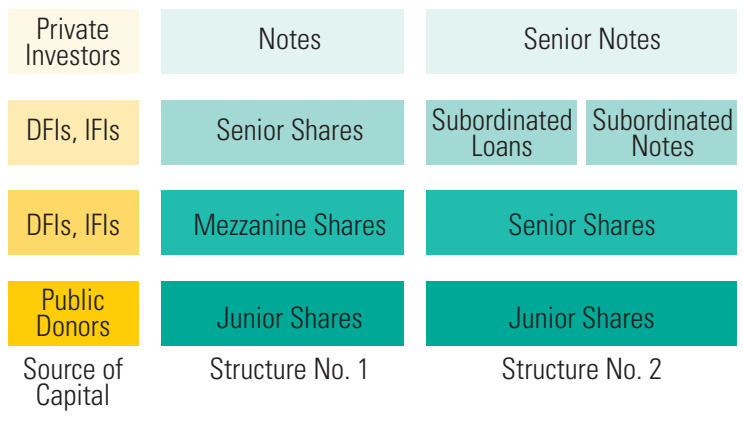

have financial structuring skills and understand what potential investors are looking for can make a meaningful contribution to the design and application of layered capital structures. Figure 3.2 is one example of this type of structure.

In the type of capital structures shown in Figure 3.2 , junior shares would be the first to bear any capital loss; the higher up in the structure, the more risk protection capital has. The fund can be designed so that returns generated are guaranteed to be first paid to note holders, independent of the profitability of the fund. Other investors receive their share in the net income according to their ranking. In this way, layered capital structures can use public funds to attract private capital to finance potentially profitable and sustainable investments while incentivizing additional investments and investors, managing expected returns, and diversifying the risk to investors. Funds from foundations could also be attracted into such aggregation structures.

In addition to well-designed structures, success depends heavily on finding fund managers who understand the sector well and can identify potentially profitable and sustainable deals. Also essential is proper alignment of interest and incentives to ensure that public funds are not used to subsidize unprofitable deals or deals that would not meet the targeted outcomes.

\section{Bundling Financial Instruments}

An effective way to utilize climate finance is to bundle one or more financial instruments with technical assistance (Box 3.1). Bundled packages have the potential to offer more comprehensive solutions to FIs and other parties to help improve and expand agriculture lending and other forms of financing. Some publicly funded financial instruments that could be packaged with technical assistance are:
- Grants;

- Senior debt, both concessional and nonconcessional; preferably with medium and long-term tenures;

- Mezzanine debt instruments, often with conversion, subordination, deferral, and other features, usually on concessional terms;

- Guarantees and risk-sharing mechanisms, usually on concessional terms;

- Local bond issues to enhance the availability of local-currency financing;

- Equity, often more patient or willing to cap returns; and

- Performance-based mechanisms, such as payments or reductions in interest rates or principal amounts if agreed milestones are met.

The bundling of several instruments at a time may prove critical to providing more comprehensive solutions to financiers and private actors while also increasing the efficacy and efficiency of the resources allocated to each intervention. Caution should be taken, however, in both structuring innovative financial vehicles and bundling multiple financial instruments so as not to unduly complicate the structure to the point that transaction costs become prohibitive or the success of the financial package is compromised.

\section{How Do PPPS, Investment Vehicles, and Bundled Financial Instruments Work Together?}

PPPs and investment vehicles alone will not suffice to both expand the amount of liquidity and expertise and make sure they are channeled all the way down to smallholder farmers and SMEs. It will be necessary to design more innovative finance models in which, for instance, PPPs use these investment vehicles (layered capital structure) to then channel finance flows to FIs that in turn on-lend to smallholder farmers, SMEs, and investment projects. An example of this finance model is the one used by Finance in Motion (Figure 3.3; see also Box 3.2).

Where they are able to catalyze additional capital, sources of finance will need to identify the best entry points to direct climate finance into agriculture effectively and to link FIs directly to smallholders and agricultural SMEs. To overcome the barriers the agricultural sector faces to access finance, sources of finance will have to consider a diverse range of initiatives. To this end, climate finance can be highly effective in facilitating and accelerating initiatives and increasing their effectiveness. 


\section{Box 3.1. Peru Case Study: Global Canopy Program - Unlocking Forest Finance}

The region of San Martin in northern Peru is at the frontier of Amazon deforestation. Supply chains for coffee, cocoa, and rice provide livelihoods to smallholders, but it is often cheaper to expand into the forest frontier than try to make cultivated land more productive.

Unlocking Forest Finance (UFF) is a project of the U.K. Global Canopy Programme in collaboration with local partner Centro de Desarrollo e Investigación de la Selva Alta (CEDISA). It will provide smallholders with access to low-cost, long-term finance, along with training in sustainable farming practices. Investment in the supply chains will cost over US\$300 million. A bond issue in international markets will access billions in global debt capital and provide necessary funding to local financial institutions (Fls), which will use the funding to invest in targeted supply chains.

UFF will be more attractive to local Fls if they can use the lower interest rates available on international markets to refinance their existing portfolios of environmental loans. Initially, these loans will be warehoused in a special purpose vehicle (SPV) managed by a national bank. The SPV will then issue a bond; proceeds will refinance the warehoused loans and provide capital for new loans within the UFF project.
Since agricultural lending in rural Peru entails a variety of risks, international investors might demand a high return. This could create a floor on the interest rates offered to smallholders. To manage borrowing costs, the bond issue first will seek to leverage the favorable credit rating of a national development bank. The underlying loan pool will then be securitized (cash flows will be earmarked for bond coupons and capital repayments), which should provide comfort to investors in lieu of higher interest rates. Finally, major climate funds like the Global Environment Facility could provide first loss or junior equity, a repayment guarantee, or both.

While green bonds-which finance environmental activities - are increasingly popular in the developing world, they must meet strict standards to qualify as "green." Institutions issuing green bonds require both financial and technical assistance to achieve this. UFF's partner, the Climate Bonds Initiative, will provide advice on achieving green certification for UFF's San Martin bond. The actual costs of certification could be met by grants from donors.

Figure 3.3. Sample Finance Model for Finance in Motion

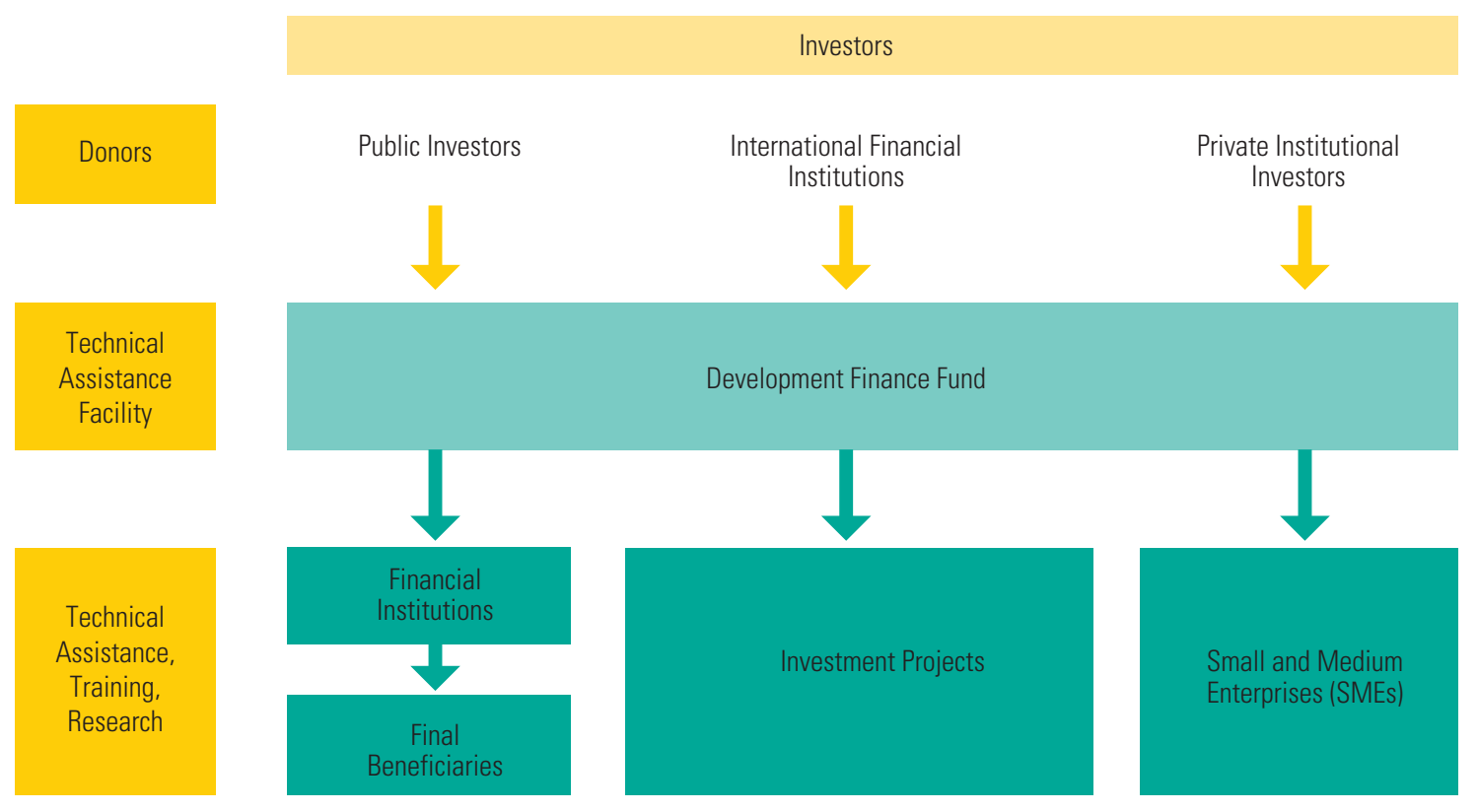

\section{Climate Finance Entry Points into Agriculture}

This section presents a number of initiatives that, properly designed and applied, can increase financing flows to agriculture, specifically to smallholders and agricultural SMEs. Moreover, these initiatives have considerable potential to ensure that lending to agriculture contributes to climate-smart outcomes.

These initiatives focus on creating the conditions necessary to develop an ecosystem that allows all who are directly or indirectly involved in the provision of agricultural finance to improve the links between FIs on the one hand and smallholder farmers and SMEs 


\section{Box 3.2. The eco.business Fund Case Study}

Launched in 2014, the eco.business Fund is an impact fund that invests to support biodiversity conservation and sustainable resource use while also generating financial returns. It is structured as a public-private partnership, with different capital tranches offering a diversified risk-return profile for different categories of investors. Public investors, development finance institutions, and donors provide first-loss capital, taking on more risk in order to protect private investors that own senior notes.

The Fund channels its financing to businesses that hold a certificate for sustainable production, (e.g., from the Rainforest Alliance) or those that have a measurable positive impact on biodiversity. The average investment is US\$5-10 million, and most are for up to 10 years. Most financing is provided to local Fls, which then loan to suitable businesses; up to 15 percent of capital is directly invested in high-impact businesses or projects. Funding is complemented by a dedicated development facility that offers technical assistance to financial institutions and their clients.
In one case, the eco.business Fund made a US\$10 million senior loan to Costa Rican Scotiabank to provide financing for environmentally certified businesses in Costa Rica, such as Global GAP and the Marine Stewardship Council. Scotiabank already has an established portfolio of agricultural and fishery clients and is using the loan funds both to strengthen relationships with existing partners and to identify additional candidates that align with the aims of the Fund. The loan to Scotiabank is combined with technical assistance for bank staff to increase their understanding of certification processes and biodiversity conservation.

The success of the eco.business Fund lending model shows that capital tranches with diversified risk-return profiles can be used to attract private investors, and that partnering with local Fls makes it easier to direct funds to suitable businesses. The eco. business model also demonstrates that offering technical assistance along with financing can significantly enhance the positive impact of investments. on the other. Such initiatives may include the use of climate finance to improve the enabling environment, such as the policies and regulations necessary to mobilize and channel financial flows to farmers and agricultural SMEs; new mechanisms and instruments to better measure, assess, and manage risk; and cost-effective delivery channels that can reduce transaction costs.

In certain cases, combining several of the interventions and financial instruments proposed below might prove more effective than a single intervention or financial instrument alone. This chapter proposes a range of financial instruments (grants, concessional financing ${ }^{1}$, etc.) that could be used to support each of the interventions suggested, but this is not a prescriptive list and any other financial instrument could be used depending on the context and the characteristics of an initiative.

It is critically important, however, to provide technical assistance to help lenders understand and build the capacities necessary to ensure appropriate design, bundling, implementation, and effective utilization of instruments and interventions, so that greater-and more efficient-lending can be channeled directly to smallholder farmers and SMEs.

\section{Improving the Enabling Environment}

\section{Public Policy and Regulations}

The more effective and supportive the public policy and regulations - the enabling environment- the lower the barriers to agricultural lending by banks and other financiers. The most important step for governments to create environments that facilitate the flow of finance to agriculture is to adopt a "do no harm" principle that limits unnecessary interference in agricultural finance. To take this step, governments should identify and strive to replicate best practices and lessons learned about policies and regulations that reduce barriers to agricultural finance and extend its reach and depth. These may include:

- Climate-smart agricultural principles: ${ }^{2}$ Public policy makers and governments can do a great deal to catalyze additional climate-smart investments in agriculture by mainstreaming climate-smart agriculture principles into national policies and ensuring that they are widely adopted by all stakeholders including, among others, government ministries, financial service providers, SMEs, and farmers.

- Enabling agriculture finance policies: Policy makers and governments could, where necessary, encourage policy reforms that remove obstacles and promote the growth of agriculture finance and private investments and recognize agriculture as a vibrant and dynamic economic sector with great potential to accelerate economic growth. Such reforms could in turn encourage market entrants to fill in finance gaps and create a more diverse and dynamic agriculture sector. 
- Systems of property rights: Establishing or further strengthening registries, such as cadaster systems, for land ownership can improve financiers' risk management by allowing farmers to have their assets (collateral) recognized. That can increase both the access of farmers to financial services and longer-term loans and their willingness to implement climate-smart practices.

- Collateral registry for movable assets: Legal and institutional frameworks and the necessary registries to allow and encourage the use of crops, inventory, or equipment as collateral can remove a significant barrier to farmers accessing capital.

- Mobilization of deposits: Many financiers cannot mobilize borrower deposits because the regulations are overly strict or entirely absent. To address this issue, policy makers can introduce or improve regulations that enable institutions to mobilize deposits, which constitute one of the main funding costs for financiers in developing countries. Large pools of savings could also be mobilized by tapping into, among others, savings and credit cooperatives, savings clubs, and village and savings loan associations. Deposits could then help to provide the necessary liquidity for financiers to lend to farmers and especially lend longer-term to SMEs for investment purposes.

- Rural credit ratings agencies and bureaus with climate-smart components: Credit agencies and bureaus could allow FIs to benefit from credit ratings that help them evaluate the past and current behaviors of current and prospective clients, both smallholder farmers and SMEs, which would ultimately help them to determine the creditworthiness of their clients. Establishing or strengthening credit ratings agencies and bureaus can enable financiers to provide a more customized range of services. Moreover, integrating climate-smart practices and risk mitigation approaches into credit ratings would help create momentum within the markets for adopting these practices.

- Reliable contract enforcement. Effective court systems enable banks to enforce debts and recover collateral, increasing their risk management capacity and severely reducing loan defaults. Ensuring that court systems have the capacity and authority to enforce contracts can thus encourage lending to farmers. Similarly, mechanisms that allow out-of-court settlements could also be immensely useful in helping financiers to enforce contracts.

- Strong customer protection laws: Introducing or reinforcing customer protection laws is essential to ensure that borrowers are treated fairly and respectfully and avoid practices that might harm them. Important components of such laws are transparency and information disclosure in contracts, pricing and interest rates, avoidance of over-indebtedness, and privacy of client data.

- Climate-smart advisory services: Policies and regulations that facilitate the collection and provision of timely and accurate climate-smart agricultural and weather information services (through ICTs) can allow smallholders and SMEs to make informed decisions and better manage their exposure to agriculture-specific risks.

\section{Potential Role of Climate Finance}

Climate finance could be used to support national and local governments by providing grants for capacity building and financial support to build the environment necessary to enable the flow of capital from climate finance sources to farmers. Among actions that could be undertaken to facilitate this:

- Establish public policies and regulations in the areas of agriculture finance, property rights systems, collateral registries for movable assets, mobilization of deposits, contract enforcement, customer protection, agent banking, and e-money, etc.

- Draft financial, social, and environmental guidelines $^{3}$ (including metrics and monitoring and evaluation tools) to mainstream climate-smart principles into national government policies and programs.

- Establish or improve existing mechanisms to accurately estimate adaptation and mitigation financial needs for achieving the climate-smart agricultural objectives established in their INDCs, and set up a route map and an action plan.

- Develop effective screening tools that can be easily used to assess beforehand the potential climate risk of a given investment or intervention.

- Put in place monitoring and evaluation systems and tools to track budgeted government investments in climate-smart interventions.

- Set up meteorological stations to collect the necessary data and disseminate (through government agencies, ICTs, etc.) timely climate and weatherrelated information. 
- Conduct research to improve the quality of agricultural extension services and build the evidence base needed to incorporate climate change considerations, especially adaptation and mitigation activities, into those services.

- Organize international visits for those stakeholders interested in accelerating climate-smart agricultural investments to showcase successful examples elsewhere, so that they can be replicated.

\section{Facilitating and Accelerating Financial Investment}

A mismatch in information between those requiring financing and those willing to invest can stem the flow of finance between them. On the one hand, SMEs, financiers, and governments often lack access to adequate and sufficient capital to finance interventions that can develop agriculture at scale while achieving positive climate outcomes. On the other hand, while there are impact investors and potential institutional investors who are interested in investing large sums of capital in climate-smart portfolios, they are often unaware of initiatives that can absorb such investments.

The risk-reward mismatch and, more important, the information asymmetry can be addressed by establishing PPPs that function as climatesmart investment facilitators. These PPPs can play an essential role in mapping out existing national, regional, and international climate-smart initiatives that require large sums of capital and clustering them into portfolios for investors seeking to invest in social, economic, and environmentally sustainable initiatives. Another way to address the information asymmetry is to establish PPPs that function as climate- smart incubators. These PPPs could serve as aggregators of farmers and SMEs and provide brokering services nationally by identifying smaller climate-smart projects and clustering them into CSA portfolios to which FIs can then link. More specifically, different models that include both concepts could be developed to provide the following services:

Model 1 (Figure 3.4.):

- Climate-smart Investment Facilitators: Charging a fee for the service of matching investors with those FIs that have a portfolio of investments of appropriate size that are categorized as climatesmart; and

- Climate-smart Incubators: Charging a fee for the service of matching FIs with both certified CSA portfolios and CSA projects (i.e. directly with smallholder farmers and SMEs, through facilitating and development agencies, etc.)

Model 2 (Figure 3.5):

- Climate-smart Investment Facilitators: Becoming an intermediary that matches investors with investments of appropriate size that are categorized as climate-smart ${ }^{4}$ and also design adequate layered capital structures to subsequently manage and invest the assets accordingly. This model has the advantage of significantly reducing transaction costs and risk for investors as well as carefully selecting those interventions that will achieve positive climate outcomes.

Figure 3.4. Example of a Climate-smart Investment Facilitator and Climate-smart Incubator

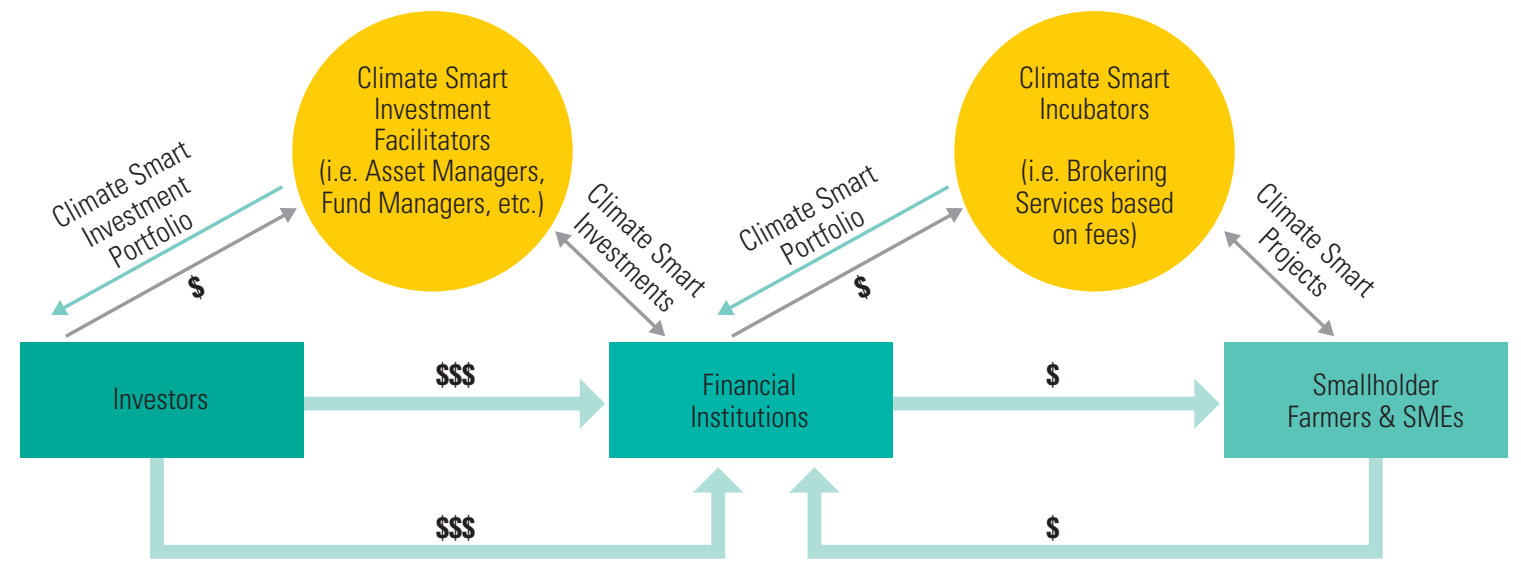

Model 1 
Figure 3.5. Example of a Climate-smart Investment Facilitator and Climate-smart Incubator

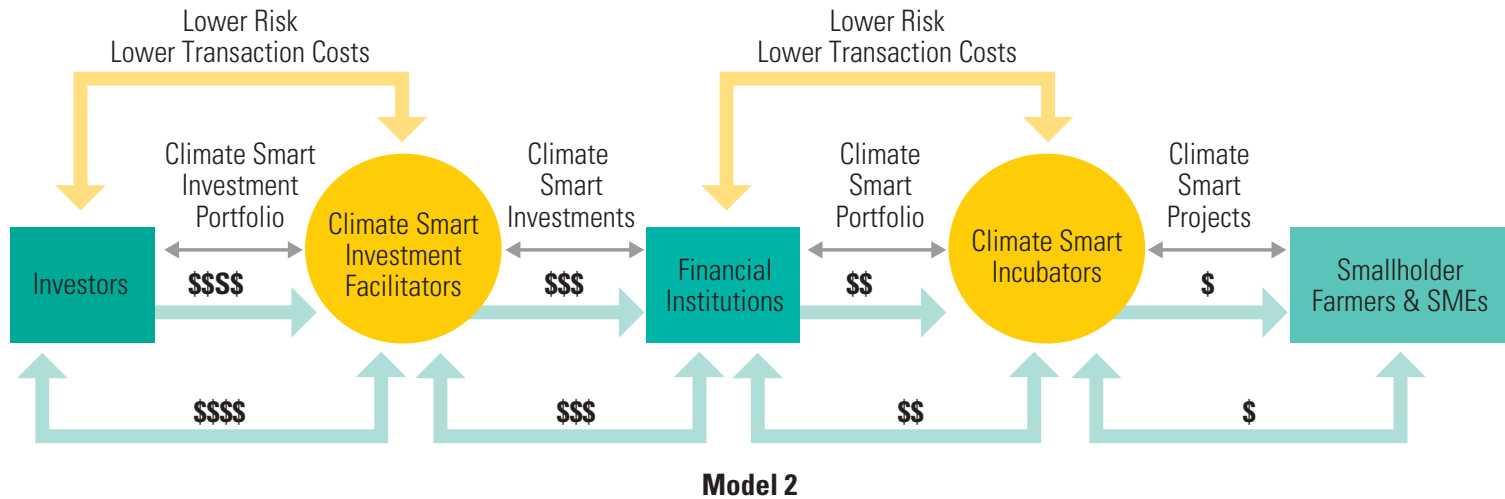

- Climate-smart Incubators: Acting as an intermediary that offers FIs a portfolio of CSA projects, raises capital with the appropriate risk and impact appetite, and manages and invests the capital accordingly. This model has the advantage of significantly reducing transaction costs and risk for FIs as well as careful selection of projects that have the potential to achieve significant positive climate outcomes.

The two models could be interchanged or developed in other innovative ways to ensure that there is a simple but constant flow of communication between financiers (climate funds, institutional and impact investors, FIs, etc.) and recipients (FIs, smallholder farmers, SMEs, etc.) that are interested in making climate-smart investments in agriculture.

Equally important to facilitate and accelerate financial investments is the critical role of technical assistance for both financiers and farmers. On the one hand, technical assistance to farmers can help to broaden their capacity to understand, finance, and adopt climate-smart interventions, which will eventually increase their capacities to adapt to climateinduced risks. That may significantly lower the risks of production over time compared to business-as-usual practices and thus improve the credit-risk profile and creditworthiness of a given farmer, which may ultimately lead to increased access to finance for climatesmart interventions. On the other hand, financiers can benefit from building their capacity to understand how famers' adoption of certain climate-smart practices and technologies can significantly minimize some of the actual and perceived risks inherent in agricultural lending and therefore increase the flows of finance to climate-smart investments.

\section{Potential Role of Climate Finance}

Climate finance could be used to support stakeholders by providing grants or concessional finance to enable the flow of capital from climate finance sources to farmers. Three different types of support are possible, for different purposes.

Grants:

- Draw up clear guidelines for climate-smart screening. The guidelines should include precise metrics, indicators, and monitoring and evaluation tools ${ }^{5}$ that can identify, assess, and measure the potential financial return, level of risk, and social, economic, and environmental impact of an investment. The guidelines ${ }^{6}$ could then be adapted to the specific context to determine the worthiness of an investment.

- Support recipient countries as they build the necessary technical and financial capacity to strengthen their readiness and their ability to access climate finance to address climate- changerelated constraints.

- Develop processes for classifying agriculture projects and portfolios that achieve positive climate outcomes based on a set of accurate metrics as climate-smart.

- Build the capacity of foundations, INGOs, and NGOs that advocate for enhancement of conducive conditions for profit-making investments in agriculture and climate-related areas.

- Improve the capacity of farmers to understand the adverse effects of climate change on their production systems, how more resilient adaptive capacities can help them to better mitigate and manage agriculture risks, and their potential for facilitating access to financing. 
- Improve the capacity of financiers to understand the potential of farmers' adoption of climate-smart practices for significantly reducing the actual and perceived risks of lending to the agriculture sector.

Concessional financing:

- Support countries that have improved their enabling environments and have viable and innovative projects to attract private capital into climate-smart investments, for example, credit lines or guarantees to financial intermediaries.

- Establish entities (possibly PPPs) that can certify or classify projects and portfolios as climate-smart; conduct economic, social, and environmental audits; and resolve any issues that may arise.

- Set up entities (possibly PPPs) that can act as CSA investment facilitators, identifying climate- smart portfolios at scale and linking them to investors (both impact investors and institutional investors that observe specific economic, social, and environmental criteria). These would greatly benefit from recruiting experienced general fund managers that have already worked in or are willing to move into the sector.

- Set up entities (possibly PPPs) that act as CSA incubators, identifying climate-smart projects and linking them to FIs.

- Encourage asset and fund management firms to catalyze additional public and private investments that can be channeled to those private actors (financiers, SMEs, etc.) that are realizing climatesmart investments in agriculture.

- Provide capital to FIs to lower their cost of funds so they can provide longer-term credit lines to farmers achieving positive climate-related outcomes.

A combination of grants and concessional financing:

- Crowd in additional capital from both the public and private sectors to support the development of the necessary agriculture financial infrastructure (credit bureaus, land registries, collateral registry for movable assets, etc.).

- Set up innovation windows where companies and government can present ideas that dramatically improve access to finance for climate-smart investments in agriculture.

\section{Risk Management Mechanisms}

To recognize, measure, and manage effectively the risks involved in agricultural lending, financiers must establish or reinforce holistic risk management frameworks. The risk management strategies and instruments that are appropriate are very contextspecific; because there is no one-size-fits-all solution, they may vary according to the client, the market, and trade conditions. This context-specificity requires financiers to assess and measure risks thoroughly and continuously in order to estimate accurately the likelihood of occurrence, exposure, and magnitude of effect.

To establish effective risk management frameworks, financiers need to build both their skills and their capacity to understand their clients and the markets and the risks to which they are exposed. This understanding will allow them to customize contextspecific solutions and help them to manage risks better, reduce costs, expand their agricultural finance portfolio, and still increase their margins.

The more comprehensive and customized the risk management approaches that are used simultaneously by financiers, the more likely it is that managing risk in general and agriculture-specific risks in particular will be effective. The following mechanisms, if designed and applied appropriately, have significant potential to help financiers manage risks better and increase liquidity, in the form of both short-term working capital and longer-term investment capital, for smallholder farmers and agricultural SMEs.

\section{Rural Credit Rating Agencies and Bureaus}

One of the key challenges that financiers face in lending to smallholders and SMEs is that the information available to creditors and to borrowers is asymmetric. Well-functioning rural credit bureaus allow financiers to access up-to-date information on the past and present credit behaviors of current and prospective clients so that they can better evaluate the creditworthiness of potential debtors, monitor their credit circumstances, and make informed decisions on credit and loan agreements. Timely access to such data can eliminate the information asymmetries and enable financiers to significantly improve their credit risk assessments and their portfolio management generally. This can lead to more lending to agriculture and more efficient and lower-cost credit markets (WB 2011). Moreover, it can have a very positive effect on the entire financial ecosystem by enhancing overall financial supervision and financial sector stability.

The availability of rural credit rating agencies also has a positive impact on borrowers because 


\section{Box 3.3. Ecuador Case Study: Credit Bureaus for the Rural Poor}

In the late 1990s, Ecuador suffered a profound banking crisis that caused a huge drop in GDP, pushed up unemployment, and increased poverty across the country.

In response, in 2003 the government introduced enabling regulations issued by the Superintendencia de Bancos y Seguros (SBS) that permitted the establishment of private credit bureaus and the sharing of data formerly protected as borrower rights. These replaced the public credit registry, which had collected information only from regulated lenders, leaving out the largely unregulated micro-lenders. Six credit bureaus were licensed, all receiving client data from SBS.

To foster the inclusion of the most vulnerable populations, who mainly lived in rural areas, and to share payment histories between micro-lenders and credit bureaus, in 2005 Red Financiera Rural (RFR) launched the SERVIR pilot project. At that time microlenders, which served more than 1.7 million largely rural clients, were not mandated to share their information. Joining the pilot were 10 micro-lenders, nongovernmental organizations and cooperatives, from the two poorest Ecuadorian provinces. The bureau Credit Report was selected as partner, facilitated by RFR. RFR also provided training on how to diagnose micro-lender processes, data, and technological systems.

The results of project SERVIR were very positive, enabling it to expand to more Microfinance Institutions (MFIs) across Ecuador. Between 2004 and 2006, MFI portfolio volumes grew by 53 percent, the number of clients by 33 percent, and the average loan amount from $\$ 1,800$ to $\$ 2,400$. Over this period, credit default rates (1 day) fell from 41 to 10 percent.

A key factor in Credit Report's success was the unique access to data on borrowers that it had at the base of the pyramid through RFR's members. This gave Credit Report better market coverage than its competitors. Since 2011, Credit Report has been the only one remaining of the six initial credit bureaus in Ecuador. financiers can quickly and effectively conduct credit assessments of those clients with a good credit history. This translates into enhanced access to lower-cost capital that can be invested in productive activities. Moreover, it can facilitate farmers' access to longer-term finance, since a solid credit record is likely to significantly reduce their risk profile (Box 3.3).

\section{Potential Role of Climate Finance}

Climate finance could be used to provide grants, concessional finance, or both to create the conditions necessary to set up effective rural credit bureaus. Two different types of support could be provided.

Grants:

- Establish minimum standards and advocate with authorities to adopt the General Principles for credit reporting systems (WB 2011).

- Build the capacity of rural credit bureaus to collect, validate, and disseminate data.

- Draft and put in place guidelines (with metrics and monitoring and evaluation tools) that incorporate climate-smart principles into credit records so that investments can be tracked nationally.

Concessional financing:

- Crowd in additional capital, both public and private, to support the establishment or improvement of effective rural credit rating bureaus.
- Build the capacity of credit bureaus to provide added-value services, such as anti-fraud tools, portfolio monitoring, debt collection, and assessment of the climate-smartness of a borrower's performance.

- Develop the tools necessary to incorporate climate-smart principles into credit scoring, so that financiers can assess how creditworthy individuals are and how increased productivity and resilience can impact their ability to successfully borrow and invest capital.

- Roll out trainings to build FI capacity to understand and become active members of rural credit bureaus.

It is important to note that the proposed interventions could only be supported by concessional finance if they have serious potential to become financially sustainable businesses.

\section{Guarantees}

By using triangular structures to transfer a portion of the risk from the originator of the loan to a third party who is not the borrower, these risk-sharing arrangements are generally used to expand financing in agriculture. On the premise of lowering or eliminating a lender's potential initial losses from default, guarantees incentivize creditors to overcome their risk aversion to financing agricultural 
borrowers. Guarantees vary in nature and in operation, in the coverage they provide, and in the types of investments that they secure. They can be particularly useful for overcoming entry hurdles, such as supporting new financing models for rural smallholder farmers and SMEs that are not considered creditworthy due to, among other problems, their perceived higher risk, little or no collateral, seasonal activities, and irregular cash flows. Guarantees can also be relevant when banks are reluctant to lend due to uncollateralized loans that require significant reserves.

In other sectors, climate finance has already been used to provide first-loss or partial-credit guarantees to mitigate the perception that certain segments are expected to have higher losses. Some FIs have noted that credit lines are more effective than guarantees for motivating them to move into new markets because they provide the necessary capital (often off-balance sheet) to enable them to invest (Box 3.4).

Whether through risk-sharing guarantees or credit lines, these types of mechanisms that incentivize local financial actors to deepen their sector lending often require additional technical assistance to build internal capacity within the local FIs. In these circumstances, technical assistance can help train investment staff to assess both investments further down the agriculture value chain and investments in segments that are not familiar to the institution.
Guarantees, used carefully, have the potential to allow lenders to enter new markets and provide financial services to clients who previously were underserved. Some of the potential benefits for smallholders and SMEs are:

- Reduced collateral requirements (Hamp et al. 2013);

- More customized financial products that better suit the seasonal need of farmers;

- More favorable loan conditions, such as lower interest rates;

- Longer-term loans, which enable borrowers to invest in, e.g., equipment and added-value infrastructure;

- Longer repayment periods that enable borrowers to finance agricultural investments and seasonal activities; and

- More cost-effective delivery mechanisms to reach farmers, because they are located in rural areas, where transaction costs are substantially higher than in urban areas.

Guarantees do not release a bank from its obligation to fully understand and assess the risk of agricultural loans; it still has to assess the sustainability of such lending and have the capacity to rate loans appropriately. However, as suggested by KfW, financiers could also use guarantees to capture agriculture-specific risks by carrying out a horizontal segmentation of risk by "tranching" an agricultural

\section{Box 3.4. Ethiopia Case Study: Farmers Access Finance Through Credit Guarantee Services}

While coffee production is a mainstay of Ethiopian agriculture, Ethiopian coffee cooperatives are relatively weak and poorly managed, and coffee sector borrowers are often limited by price volatility and other fiscal constraints. The CFC/ICO/Rabobank Foundation/Rabobank Rural Fund financing project aims to address these challenges by helping cooperatives access finance in a sustainable way, allowing them to improve coffee quality and raise the incomes of their producer members.

The project set up a credit guarantee scheme amounting to US $\$ 2.25$ million to enable banks to use guarantees as an alternative to traditional collateral. A risk-sharing agreement between the Rabobank Foundation and CFC covered half of any losses incurred through lending to farmers. The Rabo Rural Fund managed guarantees in the form of funds. Rabobank International Advisory Services also provided technical assistance to banks to train cooperatives on financial literacy and corporate governance.
Of 42 Ethiopian cooperatives identified at the outset, 22 were selected to participate in the credit scheme, and templates and guidelines for preparing business plans were drafted so that these cooperatives could apply for loans to finance the coffee season. The guarantee scheme provided working capital loans amounting to over US\$700,000 to 11 cooperatives, all of which received their loans directly from the bank for the first time in their history. As this phase was closing, the bank reported a 98 percent loan recovery rate.

Having had no previous history of accessing loans, these cooperatives now feel empowered to access loans independently. Key factors in this success were the capacity-building and education activities undertaken in Ethiopia since the start of the project, and the guarantee scheme that provided support for lending to clients that historically would have been excluded due to lack of collateral. 
Figure 3.6. Portfolio Tranching to Segment Risk Types

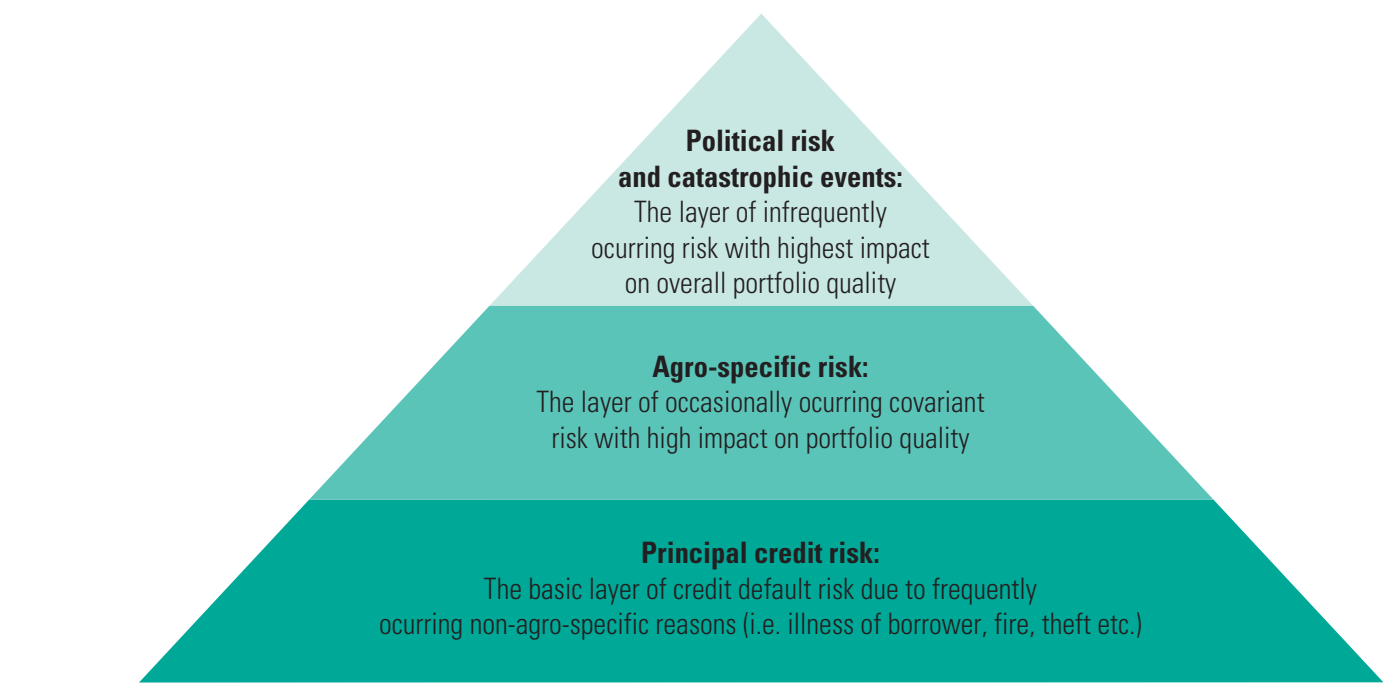

Source: KfW.

loan portfolio that identifies agro-specific risks more accurately than traditional vertical guarantees, which only cover credit risks (KfW 2014). Tranching a portfolio (see Figure 3.6) could offer an alternative to insurance products.

\section{Potential Role of Climate Finance}

Climate finance could be used to support FIs through grants and concessional lending to increase the amount of agriculture lending to farmers and SMEs. Two types of support could be provided.

\section{Grants:}

- Build FI capacity to segment their portfolios so that they can benefit from innovative structured guarantees to lend to the agriculture sector.

- Support FIs in improving their risk management capacities to maximize the impact of the guarantee and the sustainability of the long-term outcome.

Concessional financing:

- Provide the (off-balance sheet) resources necessary to motivate FIs to move into new agriculture markets.

- Encourage FIs to lend to the agriculture sector by reducing the lender's perception of the risk of agricultural loans.

- Encourage FIs to provide more favorable loan terms and conditions for farmers, reduce collateral requirements, and offer longer repayment periods for agricultural loans to enable farmers to finance agricultural investments (KfW 2013).

\section{Insurance}

Agricultural insurance allows smallholders and SMEs to transfer a risk of loss to a third party in exchange for a premium or a guaranteed and quantifiable small loss to prevent a large and possibly devastating loss. Some types of insurance deal specifically with agriculture-specific risks that cannot be mitigated even where sound risk mitigation techniques (such as irrigation and pest management) have been effectively applied. These types, such as production, weather, and commodity price insurance, can cover crops, livestock, fisheries, and forestry, among others. They are especially useful for covering losses from adverse weather and other events beyond the control of farmers, entitling the farmer to partial or full indemnification. Moreover, they can serve as collateral for agricultural loans and provide a safety net for investments.

Insurance based on PPPs tends to be more effective than purely private or purely state-organized systems (KfW 2013) because it is often more profitable and more sustainable. However, for insurance to work effectively (either an index or an indemnity-based insurance product), there needs to be a supportive legal, institutional, and organizational framework in which insurance and other risk management tools can function efficiently. 
Insurance also needs to be customized to the developmental stage and structural differences (such as the revenue differences of large, mediumsized, and small farms) of a given agricultural sector. Moreover, it can be targeted to the level of both the individual and the aggregate (especially in the case of weather-index-based insurance) where the basic risk can be absorbed by the aggregating body. This can also apply to FIs, which can insure a certain segment of their portfolio at risk by transferring that risk to the third-party insurer.

Insurance also has significant potential to help farmers and financiers manage agriculture-specific risks, although it tends to work better when bundled with other financial products as it becomes more effective at protecting all parties-farmer, creditor, and off-taker behind the loan (IFC 2012). Insurance coverage for agriculture risks-especially climaterelated weather risks-is widely recognized as a missing financial instrument in most markets (Box 3.5). Where it is available, however, it can play a critical role in enhancing the financial stability and creditworthiness of farmers as a market segment. Unlike most risk-sharing mechanisms structured with FIs, insurance can mitigate the risks of extreme events, such as flood or drought. Parametric insurance approaches in particular are seen to be valuable in helping farmers to manage shocks, particularly when climate-related weather events depress crop yields.
However, insurance as a financial product may face greater resistance from farmers than other forms of financing, in part because in many countries, there is considerable distrust of insurance. Many farmers are fearful that premiums paid will not result in benefits when claims are made. In many places, whether insurance products become widely adopted depends on the product being tested, the risk-adjusted costs of being affordable, and accessibility to payouts when required.

Furthermore, the financial viability of agricultural insurance products will depend heavily on the impacts of climate change, which for any production-related risk will increase the frequency and severity of hazards, which will inevitably push up the costs of insurance. Insurance products could be more successful combined with other efforts to transform agriculture practices in light of climate change. Hence, agriculture insurance should accompany climate-smart investments for mitigating and adapting agriculture to climate change, with insurance taking up the residual risk.

\section{Potential Role of Climate Finance:}

Climate finance could be used to ensure the necessary conditions to promote the development and use of appropriate insurance mechanisms by providing grants and concessional financing. Two types of support could be provided.

\section{Box 3.5. Kenya Case Study: Input-linked Weather Insurance - Syngenta Foundation and UAP Insurance}

Pre-commercial growers often cannot easily afford and access insurance products. In partnership with UAP Insurance, one of the leading insurance companies in Kenya and Uganda, the Syngenta Foundation for Sustainable Agriculture aims to address this issue by offering the simple and affordable weather insurance product "Kilimo Salama" (Kiswahili for 'safe farming'). Supported by the Global Index Insurance Facility (GIIF) and agribusiness partners such as Syngenta East Africa Limited and the fertilizer company MEA, the short message service-based insurance scheme has been scaled up across Kenya.

Via a mobile phone application, smallholders buying agricultural inputs from local agro-dealers are linked to the insurance program. Simply scanning the barcode affixed to a product can set up a contract between a farmer and UAP. Smallholders pay only half the premium; Kilimo Salama's agribusiness partners pay the other half, which makes the insurance affordable for rural dwellers. In case of climate extremes, farmers are immediately compensated for yield losses through a mobile money transfer ser- vice, which substantially reduces transaction costs. Payouts are calculated based on data from solar-powered local weather stations, which regularly update rainfall quantities and the weather conditions near individual farms.

Results from the 2009 season, when there was a severe drought, showed that through two weather stations the product offered payouts to all 200 maize farmers that it covered, covering 30-80 percent of their insured maize seeds. Syngenta paid the premium in full. During the 2010 season, the product covered 12,000 farmers through 25 additional weather stations, and Syngenta paid half of the premium. That year, 1,200 of these farmers received payouts for 10-50 percent of their insured inputs. In the following season, Syngenta launched "Kilimo Salama Plus," which expands the insurable sum per farmer to the expected yield value of a wider array of crops, including wheat, beans, potatoes, and sorghum. The product was also expanded to contract farming arrangements for agribusinesses. 
Grants:

- Train insurer staff in how to design and deliver agriculture coverage.

- Support the collection of climate and weather data and information on which to build farmer user services (e.g., early warning systems) and insurance products.

- Pilot ways to link financiers and insurance companies, among others, with providers like HUGinsure that can provide risk management and risk mitigation instruments for social impact investment.

Concessional financing:

- Provide capital to insurers to design and offer appropriate agriculture insurance products (such as weather and crop) for farmers, aggregators, SMEs, and FIs.

- Pilot new PPPs among meteorological, insurance, and financial providers.

- Provide risk-sharing or other low-cost financing to help offset the risk-adjusted costs for consumers or other sectors of the market where the need is significant but the ability to absorb the costs is low.

- Develop innovative business models that can provide risk management and risk mitigation instruments for social impact investment interventions (climate-smart investments in agriculture through new channels).

\section{Agriculture Value Chain Finance}

Traditionally, financiers have been reluctant to lend to smallholders and agricultural SMEs due to the high risk and transaction costs involved. However, some of the risks can be managed effectively by using a value chain finance (VCF) approach. A VCF approach consists of providing financial products and services based on business relationships between actors within the same value chain. This section focuses specifically on the agriculture value chain, in which FIs are the main source of financial products and services. The VCF approach encompasses a comprehensive assessment and understanding of the entire value chain, rather than a simple credit risk assessment of the borrower, including the links between activities and value chain actors, their financing relationships and physical and informational flows, and the subsequent design of customized financial products that meet the needs of the different actors within the value chain.
The VCF approach generally includes working with individual farmers through farmers' associations, aggregators, and other forms of collaborative enterprise, thereby enhancing farmers' capacity to diversify, transfer agriculture-specific risks, and create economies of scale in market transactions, all of which heighten the negotiating power and profitability of farmers. The risks and costs of delivery and monitoring are thus reduced, enhancing not only lending but also access to a broader range of services, such as payments and insurance that were previously beyond the reach of producers and other value chain actors. There are many examples of banks expanding lending to agricultural sectors by working with aggregators, who act as agents for the banks with their suppliers. As a result farmers who had been financially excluded could receive pre-season financing on a scale never before achieved, and often at a cost substantially below the rates offered by informal lenders (Box 3.6).

Moreover, this increase in financial services allows banks to take in more deposits, increase and diversify their portfolios, and develop a long-term growth strategy.

\section{Potential Role of Climate Finance}

Climate finance could support parties within the value chain by providing grants and concessional finance to create a conducive environment that promotes the expansion and adoption of agriculture VCF. Three types of support could be provided.

Grants:

- Train staff to map out catchment areas and identify actual and potential value chains.

- Train staff to identify aggregators and farmers that are integrated into value chains.

- Train staff to assess climate-smart criteria and deliver VCF services that achieve positive climate outcomes.

- Pilot new partnerships to integrate farmers into new value chains.

Concessional financing:

- Pilot innovative ways, through climate-smart incubators, to aggregate farmers engaged in climate-smart practices.

- Pilot different VCF models that can integrate smallholder farmers outside of value chains or in loose value chains.

- Pilot innovative ways to tighten loose value chains through "new age" aggregators, who are 


\section{Box 3.6. India Case Study: Value Chain Finance - HDFC Bank}

In India, most smallholder farmers still operate within loose supply chains and are thus left alone in negotiating sales, acquiring finance, and improving management techniques to cope with climate change. In order for Indian smallholders to access technology and better manage production, market risks, and climate risks, HDFC Bank introduced a Value Chain Finance (VCF) model.

HDFC Bank's VCF model aims to address both the primary barriers to extending finance to smallholder farmers: risk and cost. Farmers tend to be near produce collection points, which creates economic density. Moreover, all transactions between farmers, aggregators, and off-takers are captured through bank accounts, providing the bank with the credit history necessary to lend to the farmers without the need of collateral security. The bank then identifies a lead farmer or local person to function as the business correspondent, which reduces the cost of delivery to the farmer community and creates a bond of trust between the farmers and the bank. The business correspondent also sells other bank products and insurance to the farmers within the value chain and to other locals, thus earning more, which makes the model more profitable. The bank keeps a close control on business correspondents through direct and remote supervision and training to ensure service standards. Finally, an important benefit of this platform is that the bank uses it to make it easier for customers to access social transfers and government subsidies.

Results of this model have been very encouraging, with good control of both delinquencies and costs. HDFC has therefore been scaling up the model to reach the smallholder farmers who make up more than 75 percent of the rural population. Currently, the bank is increasing its digital/mobile transaction footprint within the ecosystem to keep making the model more efficient and to develop new products; it is also conducting financial literacy programs in these villages. In the next phase of development HDFC will use third-party providers to deliver value-added services to farmers to improve their productivity and sustainability. high entrepreneurial and emphasize behavioral changes in addition to the objectives set by more traditional aggregators.

- Design and pilot financial products and services that meet the needs of farmers engaged in value chains while ensuring the achievement of positive climate outcomes.

\section{Warehouse Receipts}

Lack of hard collateral prevents farmers from being able to access finance whilst financiers often both fail to assess risks adequately and seek to protect themselves from agriculture-specific risks and thus potential loan default. However, some financiers are starting to accept movable (soft) collateral from those smallholder farmers and agricultural SMEs that are either integrated into value chains or already benefit from contract farming, which allows them to use a future crop as collateral.

Of particular interest is the warehouse receipt, a type of movable collateral by which farmers deposit their commodities in secure warehouses that issue receipts in return. Financiers can then consider the deposited inventory as collateral. The acceptability of warehouse receipts requires a supportive legal and regulatory environment and secure warehouses that are well-maintained and insured if the receipts are to function effectively. They work particularly well for farmers whose commodities are not perishable (Box 3.7).

\section{Box 3.7. India Case Study: Warehouse Receipt Financing - HDFC Bank}

Small farmers often struggle to preserve their harvest in order to hold off selling until market prices and potential profits are high. Warehouse receipt financing - the use of securely stored goods as loan collateral-can address this issue while also mitigating the risk to $\mathrm{Fl}$.

HDFC Bank, one of India's leading banks (balance sheet: US\$55 billion), offers a warehouse receipt loan facility where farmers and small traders can receive loans starting from Rs. 1 Lakh (US\$2,250) against storage of about 50 different commodities in one of over 3,500 approved private or state warehouses countrywide. HDFC generally finances $65-75$ percent of the receipt value and offers moderate interest rates of 8 to 10 percent. Farmers receive the loan as soon as they deliver the warehouse receipt. Since many warehouses require a minimum lot for stocking, individual small farmers usually have limited access, but they can participate by pooling their resources through a single representative farmer.

In 2011 about 800 farmers participated, with trends indicating that participation is on the rise. Profits for farmers range between 35 and 40 percent. HDFC also benefits from low risks and losses (1-2 percent) and from spending less on collateral management and supervision, thus increasing its profit margins. Central to this model's success is the efficiency and high-quality management of HDFC's warehouse surveillance system, which includes welltrained warehouse inspectors, collateral managers, weekly markto market-valuations, and timely liquidation of stocks if there is a default. 
This type of risk management mechanism has the potential to allow farmers not only to access finance through the provision of soft collateral but also to manage specific risks, especially market risks. Through these mechanisms, farmers can store their commodities post-harvest and thus avoid losses, sell their commodities at the right time and with the right quality, etc.

\section{Potential Role of Climate Finance}

Climate finance could be used to help develop effective warehouse receipt schemes by providing grants and concessional financing. Two types of support could be provided.

Grants:

- Design and pilot warehouse receipt schemes that take into account climate-change considerations.

- Train FI staff in the use and management of warehouse receipt programs that have climate-change considerations integrated into the design.

- Set up registries of movable assets such as warehouse receipts.

Concessional financing:

- Support the purchase and development of highquality warehouses that take into account climate-change considerations.

- Pilot and purchase insurance to cover the risks associated with warehousing.

- Help roll out warehouse receipt schemes to those farmers and SMEs that adopt climate-smart practices.

\section{Climate-smart Advisory Services}

The lack of information for smallholders and SMEs about weather events, effective agricultural practices and technologies, markets, and pricing, among other subjects, substantially increases their exposure to agriculture-specific risks and jeopardizes the sustainability of their livelihoods. Agriculture advisory services, which provide information, skills, and technologies to farmers, have enormous potential to reduce their exposure to risk and heighten their skills by equipping them with the information and knowledge they need to adapt better to changing conditions and to become more resilient.

The rapid development of ICT technologies and the market penetration of mobile phones in developing countries present an excellent opportunity to expand the provision of such services at a much lower cost and more quickly. These services can provide farm-specific, weather, and market information to clients through SMS messages so that they can improve their agriculture management techniques, raise their productivity, better adapt to climate change, and obtain accurate information about when to sell their products and at what prices. Several examples of mobile applications that provide this information and store it in cloud-based systems are currently being piloted and appear to be successful (Box 3.8).

\section{Potential Role of Climate Finance}

Climate finance could be used to help create an environment that promotes effective and affordable climate-smart advisory services by providing grants

\section{Box 3.8. Philippines Case Study: Climate-smart Rice Cultivation through Phone Apps}

Farmers rarely have easy access to extension services and other sources of information that can help them become more productive given the conditions of their specific situation. To help connect farmers with local extension officers via technology, in 2013 the International Rice Research Institute (IRRI) in collaboration with the Department of Agriculture of the Philippines created a decision support tool called the Rice Crop Manager (RCM).

The RCM is a cloud-based application that enables rice farmers to manage their fields more cost-effectively and thus sustainably increase their yields. The application allows agricultural extension staff to give farmers location-specific recommendations on pest, weed, nutrient, and water management. The recommendations are based on a combination of historical climate data, planting dates, weather forecasts (obtained through partnerships with meteorological services), and the answers to questions about previous yields and management practices. The extension officer can send recommendations, which can be downloaded at no cost, to the farmer's smart phone via SMS or to web-enabled computers via email.

Through improved crop and nutrient management, RCM aims to add $300 \mathrm{~kg}$ of un-milled rice to each crop per hectare per season. This additional production would amount to an extra 20,000 metric tons of milled rice for each of the 100,000 hectares of rice cultivated. The RCM is currently being diffused across the Philippines and has been embedded within the Climate Smart Agriculture Advisory Service (CSAAS) of CCAFS, the research program on Climate Change, Agriculture and Food Security. 
and concessional financing. Two types of support could be provided.

Grants:

- Train the staff of service providers on delivering climate-smart advisory services.

- Increase awareness among farmers of the purpose and the availability of climate-smart advisory services.

Concessional financing:

- Pilot PPPs with meteorological, insurance, and financial service providers and mobile network operators.

- Set up and improve meteorological stations that collect climate change and weather data.

- Develop a cloud-based pool of climate-smart information on agriculture practices, technologies, etc. that can be accessed by farmers and SMEs.

- Design and pilot new climate-smart advisory services using ICTs.

- Support new entrants in the market to increase competition and the supply of products and services.

\section{Big Data and Data Science}

Currently, there are promising innovations combining the use of mobile technologies, such as big data and data science, that have the potential to dramatically reduce information asymmetry and the associated lending risks, thus expanding access to capital for hundreds of millions of previously underserved people. Two main innovations that are already taking place (Jamal et al. 2016) relate to the ability to collect and collate new data sources ("alternative data"), both digital and nondigital, and the ability to analyze and apply this data through new methodologies ("data science").

These services analyze the digital footprint (including phone calls, text messages, Internet browsing, use of social media, airtime top-ups, utility payments, mobile money transactions) of mobile customers (from mobile phone usage, e-wallets, and mobile phone platforms) and also analyze nondigital data. The resulting "big" data are then used to assess credit risk, determine creditworthiness, and ultimately provide loans. These services at the moment are mostly directed to small short-term loans for younger tech-savvy customers in urban areas, although there are also some interesting examples of credit scoring models that use "alternative" data to target agricultural borrowers, such as those of Gro Ventures, Farm Drive, and the Grameen Foundation; firms like EFL and Arifu are also piloting programs to explore their relevance to farmers.

These types of innovation open a path to further explore the potential of such services to reduce the risk and the cost of assessing the creditworthiness of smallholders (Box 3.9). In order to do so, the

\section{Box 3.9. Big Data Case Study: Reaching Smallholders with Alternative Credit Assessments}

In order to access financial services, clients usually need to be documented and show a formal credit history. As a result, smallholders and the rising middle class in emerging markets often cannot get funding. This dynamic is changing, however, because credits are increasingly based on using advanced data analytics to assess consumer credit risks. "Big Data, Small Credit" (BDSC) scoring schemes thus often rely on nontraditional data sources, such as social media and mobile call records. Since it can significantly lower the costs of scoring, BDSC has great potential for the financial inclusion of otherwise excluded segments, and for delivering better and cheaper financial services.

An example is the big data firm Cignifi, which creates algorithms from records of prepaid mobile phones (e.g., SMS and call frequency, caller duration and network, payment patterns) to determine client credit scores and to target tailor-made products to a broader clientele. This algorithm-based ability to assess the creditworthiness of previously unbanked consumers comes at a significantly lower cost than the conventional method of determining creditworthiness.
Another case is Lenddo, which operates in the Philippines, Colombia, Mexico, and India and uses social media activity, networks, and social reputation to assess the creditworthiness of costumers. It also extends loans either directly or in partnership with other lenders. In Colombia, it was found that about 70 percent of those who borrowed from Lenddo were willing to share with it information on their social media activity and web-browsing history to improve their chances of getting a larger loan, or indeed any loan. The founders of Lenddo estimate that currently about 1.2 billion other adults with digital footprints do not have access to formal credit.

The application of BDSC is still at its infancy, and many startup companies are experimenting with markets, consumer segments, and models. Because the applied algorithms are very new compared to the long-tested credit-scoring methodologies used by traditional credit bureaus, scoring accuracy may still need to be adjusted, and new competitive modes and partnerships may arise. The hope is that BDCS will not only deliver better credit to emerging consumers but also successfully lower transaction and service costs for Fls and private businesses alike. 
following three areas will need further attention to facilitate the development of models that address the particular needs of smallholder farmers and SMEs (Jamal et al. 2016):

- More collaboration with nontraditional groups like technical assistance providers, who may already have large data sets on the identities, behaviors, characteristics, and assets of farmers;

- More digitalization of data from government sources, extension workers, and those in agriculture value chains, among others; and

- More context-appropriate investment to allow innovations to conduct longer pilot programs.

\section{Potential Role of Climate Finance}

Climate finance could be used to facilitate emergence of the conditions necessary to further develop big data and data science business models relevant to the agriculture sector through grants and concessional financing. Two types of support could be provided.

Grants:

- Collect data from traditional and nontraditional actors in agriculture finance.

- Support firms that wish to digitize and analyze big data for use in credit-scoring models.

- Incorporate climate-smart principles in creditscoring models where feasible.

- Train FI staff in the use of such technologies to assess the creditworthiness of agricultural borrowers.

- Design and pilot big data and data science models that are suitable for farmers.

- Adapt the investment environment to allow for longer pilots that have the potential for positive results for farmers.

- Support financial institutions to adopt such credit-scoring models.

Concessional financing:

- Provide capital to new market entrants to expand alternative business models.

\section{Mechanisms to Reduce Transaction Costs}

One major constraint that financiers face in delivering financial services to smallholder farmers and SMEs is the high transaction costs involved in providing such services. Overcoming the constraints will require FIs to make substantial organizational changes by designing more cost-effective and innovative set-ups, processes, partnerships, and delivery mechanisms. Such changes would allow them to keep the costs per unit of capital lent sufficiently low to generate enough margin. This section examines several cost-effective models that, when used effectively and under the right market conditions, show promising results for expanding financial services to smallholders and agricultural SMEs.

\section{Branchless Banking}

Branchless banking refers to the provision of financial services outside the conventional network of FI branch locations. The equipment (such as ATMs and trucks) may be owned by the financier or by a partner (such as bank employees, partner employees, and agents). Branchless banking relies on ICT to conduct financial transactions through points-ofsale (POS) or mobile phones. This delivery model has the potential to substantially reduce transaction costs while increasing access to financial services for farmers in rural and other underserved areas where setting up a branch would not be financially feasible (Box 3.10). Within this type of delivery model, PPPs could be essential in enabling financiers to explore alternative, innovative, and cost-effective business models that can guarantee the delivery of secure and efficient financial services. Among options for this type of model that have been used in developing countries are post offices, branches of mobile network operators (MNOs), and value chain actors.

To maximize the potential of this delivery model, improvements are needed in, among other areas, the applicable regulations, the number of service points, the simplification of processes to open accounts, and the authorization of more providers to offer payment and e-services.

\section{Potential Role of Climate Finance}

Climate finance could be used to support those interested in creating the environment and infrastructure necessary to promote branchless banking services by providing grants and concessional financing. Three types of support could be provided.

Grants:

- Support adoption of regulations that promote the establishment and growth of branchless banking.

- Organize and strengthen agent networks and their management. 
Box 3.10. Pakistan Case Study: Branchless Banking - United Bank Ltd.

In Pakistan, only 10 percent of the adult population has bank accounts at formal financial institutions, and few of the account owners are in rural areas. To improve smallholder access to banks in rural Pakistan, in April 2010 United Bank Ltd. (UBL) launched its "Omni" branchless banking program. With more than three million clients and over 1,200 branches, UBL is Pakistan's second-largest private bank.

For this program UBL has installed full-service kiosks, "Omni Durkaans," at retail partner locations in over 500 cities and towns. At these locations farmers who set up an UBL account are linked to an Omni mobile number. Account holders must maintain a minimum balance of Rs 100 (US\$1.15), and can choose between weekly, monthly, annual, or pay-as-you-go options. Clients can also receive a debit card and make transfers at one of 500 ATM network locations. Clients without mobile phones can pay bills or transfer money through an over-the-counter transfer service, which has become very popular.
Through Omni and its extensive network of agents, clients can now easily and cheaply qualify for microloans, transfer money, and make payments via mobile phone or full-service kiosks. Both clients and UBL also benefit from lower transaction costs, which otherwise limit the ability of clients in rural areas to access financial services. UBL also has created links with microfinance institutions to accept loan repayments.

Over the next five years, UBL expects 15-20 million people to benefit from these services. An additional benefit is that UBL has also partnered with nongovernmental and governmental bodies to facilitate payments for support and relief programs, benefiting millions of Pakistanis. Through the Omni kiosks, two million Pakistanis have received payment from flood relief and income support programs and the World Food Programme.
- Train agents as climate-smart investment brokers so that they can identify borrowers engaged in climate-smart practices and link them to creditors.

- Design and pilot innovations to overcome operational constraints (e.g., agent liquidity, a high number of inactive members).

- Identify partners and train staff on delivering branchless banking services.

Concessional financing:

- Design and pilot new delivery models based on ICT use.

- Purchase the necessary equipment and construct adequate infrastructure (branches, ATMs, POS, etc.).

- Provide financial support to new market entrants that demonstrate innovative business models, products, or delivery channels.

\section{A combination of grants and concessional financing:}

- Pilot and scale up PPPs with institutions and organizations interested in providing financial products and services to farmers who have adopted climate-smart interventions.

\section{Mobile Financial Services}

Given the skyrocketing market penetration of mobile phones and the increasing competition of MNOs in developing countries, providing financial services via mobile devices has enormous potential to deliver affordable financial services while significantly reducing FI transaction costs. FIs and MNOs usually offer mobile access that can be used for a wide range of services, such as loans, savings, domestic transfers, and insurance. Such services can be accessed through a variety of channels, such as those linked to electronic accounts (wallets) and over-the-counter (OCT) transactions that do not require clients to have an account.

These types of services are already present in 93 countries, offering a total of 271 services (GSMA 2015). It also appears that there is still substantial demand for mobile financial services, which showed a 31 percent increase in registered accounts (to 411 million people) in December 2015 (GSMA 2015). The demand represents a major opportunity to further develop enabling environments, a wider portfolio of services that can achieve greater market uptake, and the engagement of inactive members of financial services so that more farmers can be financially included.

Moreover, mobile financial services have great potential to link farmers who were previously financially excluded to bankers and allow FIs to mobilize large amounts of deposits, which could then be used to lend to farmers, provide a source of digital data and of credit/financial transactions history, and be used as collateral (Box 3.11).

\section{Potential Role of Climate Finance}

Climate finance could be used to help enable the conditions necessary to promote development and improvement of mobile financial services by 


\section{Box 3.11 Kenya Case Study: Mobile Banking - M-PESA and M-KESHO}

Low-income populations, especially those living in rural areas, often cannot easily access financial services and so do not have a secure or affordable way to manage and store money at formal Fls. Safaricom, Kenya's largest mobile service provider, has partnered with the Commercial Bank of Africa and Kenya's Equity Bank to launch a branchless and agent-network-based mobile phone-based service, "M-Pesa," that is helping customers to access financial services and manage and store money.

M-Pesa offers clients a straightforward and affordable way to transfer money, send remittances to rural areas, and pay bills. Client accounts are held in a trust fund at the Commercial Bank, which facilitates formal savings across socioeconomic divides while keeping transaction costs low. Lenders may also use
M-Pesa accounts together with other financing tools to establish secondary collateral sources through an integrated and farmerfocused approach.

M-Pesa is currently used by over 70 percent of Kenyan adults, and an average of 150 million Ksh (US\$1.96 million) flows through M-Pesa every day, mostly in small amounts that average just over $1,500 \mathrm{Ksh}$ (US\$20). While one of its main functions is to facilitate low-cost money transfer, remittances to rural areas in particular, it is also being used increasingly to accrue savings. It has been found that Kenyans with M-Pesa accounts are 32 percent more likely to report having savings than those without accounts. In recent years, M-Pesa has expanded to South Africa, Afghanistan, India, and Eastern Europe. providing grants and concessional financing. Two types of support could be provided.

Grants:

- Train staff in how to use mobile technologies to deliver financial services.

- Conduct sensitization campaigns to increase the awareness of farmers about mobile financial services, not only to increase adoption rates but also to promote active use.

Concessional financing:

- Support the development of a mobile money ecosystem.

- Pilot and develop PPPs with entities interested in extending mobile financial services to borrowers who have embarked on climate-smart interventions.

- Design and pilot new mobile products and services that can reach underserved rural farmers engaged in climate-smart interventions and increase market uptake.

\section{Technical Assistance to Increase Investments in Agriculture}

\section{Technical Assistance to Lenders}

\section{Development of Agriculture Finance Capacities}

To build an effective and sustainable portfolio of financial products and services for agriculture, FIs need to build the institutional capacity necessary to enable their institutions to effectively serve the agriculture sector. For instance, they could:
- Set up a clear and effective agricultural lending strategy;

- Put in place policies, systems, processes, and operational manuals to guide agricultural lending;

- Identify the mechanisms necessary to assess, manage, and quantify agriculture- and climate- specific risks; and

- Identify opportunities to grow and expand agricultural lending and effectively manage and monitor their agricultural lending portfolios.

\section{Potential Role of Climate Finance}

Climate finance could be used to help FIs and others to create the conditions necessary to promote the provision of effective agriculture financial products and services by providing grants structured around meeting milestones and targets or paid when results are achieved. Two types of support could be provided.

Grants:

- Support FIs integrating climate-smart guidelines into their policies and operations, so that they can be mainstreamed through their lending.

- Map out market opportunities to expand FI agriculture finance portfolios.

- Pilot and engage in PPPs to leverage knowledge and capacities of government and other institutions in agriculture lending practices, especially those related to climate-smart practices.

- Put in place monitoring and evaluation tools to assess the impact of the agriculture lending portfolio in terms of climate relevance. 
Concessional financing:

- Support the establishment of dedicated and specialized agriculture lending departments where necessary.

- Design structured risk management frameworks and tools to help mitigate agriculture- specific risks so that they can lend to borrowers committed to climate-smart practices.

- Help FIs to qualify for concessional financing (debt, guarantees, and possibly equity) from investment incubators.

\section{Building the Capacity of Agriculture Finance Staff}

All the interventions and financial instruments suggested above will only be effective in providing sufficient and adequate finance to the agriculture sector if technical assistance is provided to FIs to help them understand and build capacity to design and ultimately use the instruments and interventions efficiently.

Hence, a qualified and specialized lending team will be crucial if FIs are to effectively provide agriculture financial services. Such specialized teams would require staff that thoroughly understand agriculture and the economics of farming and have solid banking experience and robust credit risk assessment capacities. Providing agricultural training to existing lending staff can be highly cost-effective because they lend to all sectors throughout the year, whereas specialized agricultural experts tend to come up with overly complex financial products and also may face periods of low productivity, given the seasonality of agricultural lending (KfW 2013). Moreover, lessons drawn from the World Bank AgriFin program show that peer-to peer training (for example, bankers who have extensive experience working in agriculture lending training other bankers eager to enter that segment of the market) tends to be significantly more effective than training provided by development agencies, government bodies, or development consulting firms.

Training staff on climate-smart interventions and the benefits of farmers adopting certain climatesmart practices and technologies can make it easier for bank staff to understand the capacity of farmers to reduce production risks and thereby increase their productivity, build resilience, and better adapt to climate change, which in turn could improve their creditworthiness. This could have a positive impact on reducing the perception of agriculture in general, and of farmers in particular, as high credit risks and ultimately expanding the size and quality of the agriculture-lending portfolio (Box 3.12).

\section{Potential Role of Climate Finance}

Climate finance could be used to help build the capacity of FI staff to provide effective finance services to agriculture by providing grants structured around specified milestones or payment by results. Different types of support could be provided.

\section{Box 3.12. Cambodia Case Study: Building Agricultural Lending Skills - Amret Microfinance Institution and the World Bank}

One difficulty many financial institutions face when lending to any new sector is finding and training staff so that they have a solid understanding of the actors, dynamics, and general workings of that sector. A partnership between the World Bank AgriFin program and Amret Microfinance Institution, which recently established a new agricultural lending unit, demonstrates that a specialized agricultural lending unit can help grow a successful agricultural loan portfolio.

In consultation with AgriFin, Amret filled positions in the new agricultural unit with internally recruited personnel who were then trained in agriculture. Amret also appointed two permanent trainers to coach branch lending staff during the pilot and rollout phases on how to lend to agricultural clients and how to apply AMRET policies and procedures to agricultural lending. To supplement the training, Amret developed six agricultural sector cards - for duck, pepper, cassava, rubber, and wet and dry season rice - to educate staff about these commodities and the skills and equipment required to produce and market them.

To respond to growing farmer demand for larger loans, Amret designed a specialized, cash-flow-based AgriFin loan product. Loan officers trained in the AgriFin cash-flow-based lending methodology disburse these loans. The average agricultural loan now amounts to about US\$6,000, over four times the size of the average microloan previously offered to farmers (US\$1,300). As of October 2014, AgriFin loans amounted to US\$11.6 million, equal to four percent of Amret's total loan portfolio.

Amret is now seeing higher demand for agricultural lending from a new market of farmers whose financial needs are growing. Putting in place a specialized agriculture unit was a major factor in this growth. As a result, Amret is now considering mobile tellers as a cost-effective way to expand and scale up services to agricultural clients. 
Grants:

- Train FI staff on agriculture finance, assessment of agriculture credit risk, climate-smart investments in agriculture, etc.

- Support international exchange visits by FI staff to learn what other institutions are doing, so that they can replicate best practices.

- Help FI staff to identify reliable brokers that can provide a sufficient and attractive portfolio of climate-smart interventions, thus reducing risks and transaction costs.

\section{Customizing Agriculture Financial Products and Services}

A clear diagnostic is critical at the outset in order to identify challenges that must be tackled as well as client needs. Such a diagnostic can identify the tools and interventions most appropriate for a given case. In nearly all cases, a range of tools will be needed due to the multifaceted dimensions of the barriers to lending that must be overcome. Segmenting farmers to identify their financial needs is vital, because farmers are heterogeneous and have different needs. It is thus important to identify sub-segments of the farming population and assess their needs and constraints before designing and customizing specific solutions and products. For example, in one location, smallholders may primarily need access to working capital, payments, and remittance services, whereas larger SMEs may prefer access to longer-term credit lines and leasing services to acquire machinery and make productive investments.

\section{Potential Role of Climate Finance}

Climate finance could be used to enable FIs to meet the conditions necessary to build a portfolio of customized and affordable financial products and services by providing grants and concessional financing. Two types of support could be provided.

\section{Grants:}

- Support FIs as they conduct diagnostic studies and map out the needs of and impediments for farmers in general and those engaged in climatesmart practices in particular.

- Support FIs in integrating climate-smart principles into their portfolios of products and services.

- Conduct research on effective and affordable innovations related to credit assessment, financial products, and delivery mechanisms.
- Support the work of FIs in designing and piloting customized products and services that better address the needs of borrowers engaging in climate-smart practices.

- Train staff to deliver customized and affordable financial product and services.

\section{Concessional financing:}

- Help FIs to establish partnerships (PPPs or private partnerships) with MNOs, insurance providers, suppliers, etc. so that they can offer more comprehensive products and delivery mechanisms.

- Encourage FIs to roll out customized products and services that better address the needs of borrowers engaged in climate-smart practices.

- Support FIs that are rolling out climate-smart financial products and services.

\section{Building Borrower Capacity}

It is estimated (Dalberg 2014) that in 2011 low- and middle-income countries spent US\$191 billion on developing agriculture but only US\$8.4 billion was invested in technical assistance for farmers (US\$7 billion by governments, US $\$ 1.1$ billion by international donors, and US\$0.27 billion by corporations). Yet smallholder farmers and SMEs could greatly benefit from building their capacity and skills related to farm management, climate-smart practices and technologies, and agriculture risk managementskills that can help them to become more productive, build resilience, and better manage the adverse effects of weather events and market and price changes. Enhanced knowledge, skills, and risk-sharing mechanisms will also equip them to better adapt to and mitigate the impacts of climate change.

Moreover, an often-overlooked requirement for expanding financing to agriculture is to provide potential borrowers with the skills they need to access loans and financial services. While larger enterprises have audited accounts and financially aware staff, SMEs often do not have the requisite financial documents or staff who can prepare credible loan applications. Smallholder farmers similarly are not used to formally accessing credit and quite often they also lack financial management skills. Evidence from a variety of programs has demonstrated how much impact training borrowers can have. Failure to consider borrower capacity when designing agricultural finance programs may at times result in capable FIs failing to find credible borrowers. 
While often the barriers to increasing agriculture finance are attributed to the supply side, there are also significant barriers on the demand side, especially where food crops and less-organized value chains are concerned-and these are where the majority of smallholder farmers are concentrated. There are a number of reasons for this, such as a lack of knowledge about how financial systems work, insufficient trust in and understanding of the services available, and little capacity to generate enough revenue to repay obligations or make investments. Moreover, adoption of climate-smart interventions is likely to require additional skills and capacities and upfront investments in new technologies and practices to facilitate the transition to low-carbon and more climate-resilient agricultural practices. Smallholder farmers and SMEs therefore need technical assistance to help them build awareness and better understand the behavioral, technological, and practice changes needed to mainstream climate smartness into their agriculture interventions, and also to build the skills needed to access finance to deal with climate change.

\section{Potential Role of Climate Finance}

Climate finance grants could be used to help farmers build their capacities and expand their skill base to effectively use financial resources for agricultural activities while adapting to climate change and reducing emissions. Support could be provided to:

- Design training materials on, e.g., risk management, climate-smart interventions (especially for adapting to and mitigating climate change), and business and financial skills.

- Directly or through aggregators, build the capacity of smallholder farmers and SMEs to adopt climate-smart practices to help them understand the behavioral, technological, and practice changes needed to become more productive while adapting to climate change.

- Build up the skill base of farmers, either directly or through aggregators, to help them dismantle barriers that block demand for additional finance.

- Roll out training to farmers, directly or through aggregators, on, among other topics, business, financial, and management skills.

- Train aggregators on risk management, contextspecific climate-smart practices, and business and financial skills.

- Link farmers, SMEs, and aggregators to organizations that provide brokering services that connect them to FIs.

\section{Notes}

1. Concessional financing could refer to debt, equity, guarantees, etc.

2. These are principles that promote climate-smart investments in the agriculture sector to heighten agricultural productivity and adaptation to climate change while reducing emissions intensity.

3. The Sustainable Banking Network consists of central banks in emerging markets that have issued environmental and social guidelines that should apply to lending to various sectors, including agriculture.

4. This could be done by identifying a set of metrics that help measure the climate-smartness of an agricultural activity, project, or investment.

5. The Global Impact Investing Network (GIIN) in particular has effective monitoring and evaluation tools.

6. These guidelines could be specifically targeted to each entity interested in realizing climate-smart investments in agriculture (climate funds, bilateral and multilateral organizations, FIs, private companies, and impact and institutional investors, among others). 

Chapter 4

\section{CONCLUSION AND WAY FORWARD}

Clearly, agriculture is not only extremely vulnerable to climate change but is also a significant contributor to it, accounting for 19-29 percent of total anthropogenic GHG emissions (Vermeulen et al. 2012). Moreover, due among other factors to the growing global population and changing diets, by 2050 the sector will need to produce at least 50 percent more food to feed nine billion people. It is estimated that at least US $\$ 80$ billion annually will be needed to finance that increase in food demand; most of the funding is expected to come from the private sector (WB 2015).

In this situation climate finance can be a major catalyst for providing and leveraging additional sources of finance, both public and private, and for supporting the emergence of more effective and efficient environments that allow financing to flow to smallholder farmers and SMEs to fund investments in low-emission, climate-resilient agriculture.

To ramp up agricultural production on the scale needed, it will be essential to establish PPPs that bring together donors, governments, climate funds, development and international FIs, civil society, private and institutional investors, and others from the agriculture, climate, and financial sectors. It will also be necessary to continue to design and pilot innovative financial mechanisms and instruments that can accommodate the different risk-return profile of each of the stakeholders involved. Bundling several financial instruments and interventions can help to produce more holistic and comprehensive solutions. For instance, Finance in Motion is using layered capital structures to meet the risk appetite of each of its investors and the social, economic, and financial returns each expects. The Global Canopy
Program is designing green bonds to raise capital in international markets, which will then be channeled through local FIs. To raise additional capital, the Althelia Climate Fund is offering market-rate conservation investment products to individual private investors. All of these examples are also combining these financial instruments and mechanisms with a variety of other financial products, such as guarantees and grants for technical assistance.

There are many other promising options like those described in the case studies that can be replicated. To facilitate the rapid advancement and scale-up of such innovations, concrete action must be taken to enhance the multiplier effect that climate finance can have in supporting the transformation to low-emissions and climate-resilient agricultural systems. The following four actions could facilitate this process:

\section{- Improve and disseminate financial knowledge:} It is essential to identify the most efficient ways to support the transformation to low-emissions, climate-resilient agricultural production. In order to do so, it will be necessary to design innovative financial mechanisms, investment vehicles, and financial instruments that can provide more tailored and comprehensive solutions to the specific challenges of climate change that now confront agriculture. It will be critical to identify new ways to use these to leverage additional capital from public and private sources and find more effective avenues to direct it to smallholder farmers and SMEs. It will be equally important to allocate sufficient resources to assume certain levels of risk and to pilot and bundle innovative mechanisms 
so that a wide range of financial approaches can be tested and if successful scaled up. What will also be necessary will be to find effective communication channels to disseminate such financial knowledge and information to stakeholders so as to heighten the capacity of all involved to ensure that their climate-smart investments are effective.

- Bridge gaps and identify opportunities: Given the number of sectors (agriculture, climate, and finance) and parties (government, donors, civil society, financial institutions, private companies, and private investors, among others) that support low-emissions, climate-resilient agricultural systems, reaching common ground may not be easy. For each sector and stakeholder there are different backgrounds, expertise, and objectives and therefore often different "languages" and approaches. The lack of agreement among stakeholders on how best to promote climate-smart investments in the agricultural sector can undermine the potential for addressing the challenges in a coordinated, effective, and timely manner. It is therefore essential to effectively and consistently promote interaction between stakeholders so that all can better understand each other's characteristics, expertise, strengths, and objectives. This will be vital so that all parties can harmonize their languages and approaches and identify their commonalities and complementarities and the market niches and opportunities for collaboration these may represent. This will also help stakeholders to find more effective ways to create synergies so they can maximize their own capacities and resources.

- Promote spaces to foster dialogue and collaboration: To leverage the capacities, knowledge, expertise, and resources of all the actors involved in the agriculture, climate, and financial sectors, it will be crucial to create spaces to convene all stakeholders and promote dialogue. To that end, spaces like the Conference of Parties to the UNFCCC can act as a catalyst to bring all parties together, bridge knowledge and information gaps, and foster mutual understanding, dialogue, and collaboration. International and regional networks like the GACSA, Global Impact Investing Network (GIIN), the Global Innovation Lab for Climate Finance, and the OECD Partnership for Climate Finance and Development, among many others, can also encourage stakeholders to discuss current challenges and opportunities and identify innovative financial solutions and new ways of collaboration that can generate win-win situations for all parties. Such spaces need to bring in stakeholders from all sectors, from institutional and impact investors through climate donors and governments, from private companies and FIs to SMEs and smallholder farmers.

- Draft action plans: To transition to low-emissions, climate-resilient agriculture, stakeholders from different sectors will need to identify and agree on specific next steps, so that concrete action plans can be drawn up. These will be vital for promoting coordination among parties and maximizing resources and opportunities while ensuring that goals are met in an effective and timely manner. To this end, some of the most prominent actors in the climate change arena, such as the UNFCCC, the Green Climate Fund (GCF), and the Global Environment Facility (GEF) could take the lead in moving up agriculture on the climate change agenda and then identifying channels for flows of climate finance to the sector. 


\section{REFERENCES}

Campbell, B. 2015. "Climate Change: Half a Degree Will Make a World of Difference for the Food We Eat." Huffington Post. 9 December 2015. http://huff. to/1RNDSnYClimate Funds

Update: Climate Finance Fundamentals 11, December 2015 - The Green Climate Fund. https://www.odi.org/ sites/odi.org.uk/files/odi-assets/publications-opinionfiles/10066.pdf

CPI (Climate Policy Initiative). 2015. Global Landscape of Climate Finance 2015 Report. http://climatepolicyinitiative.org/publication/ global-landscape-of-climate-finance-2015/,

Dalberg Global Development Advisors. 2014. "Technical Assistance for Smallholder Farmers: An Anatomy of the Market." The Initiative for Smallholder Finance, Briefing 07. http://www.ruralfinanceandinvestment.org/ sites/default/files/technical-assistance-for-smallholderfarmers-an-anatomy-of-the-market-1.pdf.

Dickie, A., C. Streck, S. Roe, M. Zurek, F. Haupt, and A. Dolginow. 2014. Strategies for Mitigating Climate Change in Agriculture: Recommendations for Philanthropy. Climate Focus and California Environmental Associates, prepared with the support of the Climate and Land Use Alliance. Report and supplementary materials: www.agriculturalmitigation.org.

Edenhofer, O., et al. 2014. Climate Change 2014: Mitigation of Climate Change. Contribution of Working Group III to the Fifth Assessment Report of the Intergovernmental Panel on Climate Change. Cambridge, U.K., and New York, U.S.: Cambridge University Press.

EPA (United States Environmental Protection Agency). 2012. Global Anthropogenic Non- $\mathrm{CO}_{2}$ Greenhouse Gas Emissions: 1990-2030. EPA 430-R-12-006. Washington, DC: US-EPA. http://www.epa.gov/climatechange/ EPAactivities/economics/nonco2projections.html.

Falconer, Angela, and Martin Stadelmann. 2014. "What Is Climate Finance? Definitions to Improve Tracking and Scale up Climate Finance." Climate Policy Initiative, July 2014. http://climatepolicyinitiative.org/publication/ climate-finance-definitions-improve-tracking-scale-climate-finance/.
FAO (Food and Agriculture Organization of the United Nations). 2012. Identifying Opportunities for Climatesmart Agriculture Investments in Africa. Rome: FAO. http://www.fao.org/docrep/015/an112e/an112e00.pdf.

- 2013. Climate-Smart Agriculture Sourcebook. Rome: FAO. $h t t p: / / w w w . f a o . o r g / d o c r e p / 018 / i 3325 e / i 3325$ e.pdf. .2014. "Greenhouse Gas Emissions from Agriculture, Forestry and Other Land Use." http://www.fao.org/ assets/infographics/FAO-Infographic-GHG-en.pdf. Background Paper, Session 1, Feeding Africa conference, Dakar, Senegal, African Development Bank Group, October 21-23, 2015.

Finance in Motion. n.d. Flow of Funds: http://www.finance-in-motion.com/impact-investing/ flow-of-funds/.

GCF (Green Climate Fund). 2015. Climate Funds Update: Climate Finance Fundamentals 11. https://www.odi.org/ sites/odi.org.uk/files/odi-assets/publications-opinionfiles/9376.pdf.

GSMA. 2015. State of the Industry Report: Mobile Money. http://www.gsma.com/mobilefordevelopment/wp-content/uploads/2016/04/SOTIR_2015.pdf.

Hamp, M., F. Rispoli, and J. Agwe. 2014. Loan Guarantee Funds, Inclusive Rural Financial Services. Rome: IFAD (International Fund for Agricultural Development. https://www.ifad.org/documents/10180/ dbb92563-a227-40bf-a3fc-908f3bf0c766

HUGinsure. Social Impact Insurance. $h t t p: / / w w w . h u g i n-$ sure.com/home/?\&re $=1$.

IFC (International Finance Corporation) -. 2012. Innovative Agricultural SME Finance Models. http:// www.ifc.org/wps/wcm/connect/55301b804ebc5f379f86b f45b400a808/Innovative +Agricultural + SME +Finance+ Models.pdf?MOD=AJPERES.

Jamal, F., et al. 2016. The Rise of the Data Scientist: How Big Data and Data Science Are Changing Smallholder Finance. The Initiative for Smallholder Finance Briefing 11. http://staticl.squarespace.com/ static/565cca2ae4b02fbb0a550169/t/56b0e034ab48 dec02280a374/1454432314881/The+Rise+of the + Data+Scientist+-+ISF.pdf. 
Jarvis, A., C. Lau, S. Cook, E. Wollenberg, J. Hansen, O. Bonilla, and A. Challinor. 2011. An Integrated Adaptation and Mitigation Framework for Developing Agricultural Research: Synergies and Trade-offs." Experimental Agriculture 47:185-203. http://dx.doi. org/10.1017/S0014479711000123).

KfW Development Bank. 2013. Finance for Food, Toward New Agricultural and Rural Finance. http://goo. gl/5hHDco.

Lipper, Leslie et al. 2014. "Climate-smart Agriculture for Food Security. Nature Climate Change 4: 1068-72. doi:10.1038/nclimate2437.

Lobell, David B., Uris Lantz C Baldos and Thomas W Hertel. 2013. Climate Adaptation as Mitigation: The Case of Agricultural Investments. EnvironRes. Lett. 8. doi:10.1088/1748-9326/8/1/015012.

MacLeod, M., et al. 2015." Cost-Effectiveness of Greenhouse Gas Mitigation Measures for Agriculture: A Literature Review." OECD Food, Agriculture and Fisheries Papers, No. 89. Paris: OECD Publishing. DOI: http://dx.doi. org/10.1787/5jrvvkq900vj-en.

Meadu, V. et al. 2015. "The Paris Climate Agreement: What it Means for Food and Farming, COP21 Opens the Door for more Adaptation and Mitigation in the Agriculture Sector." CCAFS InfoNote., December 2015.

Nelson, G., et al. 2012. Food Security and Climate Change. A Report by the High Level Panel of Experts (HLPE) on Food Security and Nutrition of the Committee on World Food Security (CFS). Rome: Food and Agriculture Organization of the United Nations. http://www.fao. org/3/a-me421e.pdf.

Richards, M. et al. 2016. How Countries Plan to Address Agricultural Adaptation and Mitigation: An Analysis of Intended Nationally Determined Contributions. CCAFS dataset version 1.1. Copenhagen, Denmark: CGIAR Research Program on Climate Change, Agriculture and Food Security (CCAFS). https://cgspace.cgiar.org/ handle/10568/73255.

Salmes, S, R. Friedman, and T. Havemann. 2012. Coordinating Finance for Climate-Smart Agriculture. Ecoagriculture Discussion Paper Number 9. http://ecoagriculture.org/publication/coordinatingfinance-for-climate-smart-agriculture/.

Schmidhuber, J., and F.N. Tubiello. 2007. "Global Food Security under Climate Change.” Proc. Natl. Acad. Sci. 104: 9703-08, doi:10.1073/pnas.0701976104.
Smith, P. et al., eds. 2007. Climate Change 2007: Mitigation. Contribution of Working Group III to the Fourth Assessment Report of the Intergovernmental Panel on Climate Change. Cambridge, UK: Cambridge University Press, pp. 498-540. http://www.ipcc.ch/pdf/ assessment-report/ar4/wg3/ar4-wg3-chapter8.pdf.

Tubiello, F. N., et al. 2014. Agriculture, Forestry and Other Land Use Emissions by Sources and Removals by Sinks. 1990-2011 Analysis FAO. http://www.fao.org/ docrep/019/i3671e/i3671e.pdf.

UNFCCC (United Nations Framework Convention on Climate Change) 2015. https://unfccc.int/resource/ docs/2015/cop21/eng/l09r01.pdf.

Vermeulen, Sonja J., Bruce M. Campbell, and John S.I. Ingram. 2012. "Climate Change and Food Systems." Annual Review of Environment and Resources 37: 195-222.

World Bank. 2011. General Principles for Credit Reporting. http://goo.gl/fuMObs.

—_. 2014a. Global Findex. Financial Inclusion. http:// www.worldbank.org/content/dam/Worldbank/Research/ GlobalFindex/WB_GlobalFindex_GlobalInfographic_ 0406_final.jpg.

—. 2014b. Agricultural Credit Risk Management Training Manual, Module 3. World Bank AgriFin. http://agrifinfacility.org/sites/agrifinfacility.org/files/alloyd/392/ Module\%203\%20manual_Agricultural\%20Credit\%20 Risk\%20Management_Centenary.pdf.

—_. 2015. "World Bank Agriculture Finance." http:// www.worldbank.org/en/topic/financialsector/brief/ agriculture-finance.

—.2016. "Agriculture \& Rural Development." http://data. worldbank.org/topic/agriculture-and-rural-development.

Wheeler, T., and R. Tiffin, R. 200). "Costs of Adaptation in Agriculture, Forestry and Fisheries." In Assessing the Costs of Adaptation to Climate Change: A Review of the UNFCCC and Other Recent Estimates, edited by M. Parry et al., pp. 29-39. London, UK: International Institute for Environment and Development/Grantham Institute-Climate Change and the Environment.

Williams, T., et al. 2015. "Climate Smart Agriculture in the African Context." Background Paper for Session 1: Unlocking Africa's Agricultural Potentials for Transformation to Scale; Background Paper. http:// www.afdb.org/fileadmin/uploads/afdb/Documents/ Events/DakAgri2015/Climate_Smart_Agriculture_in_ the_African_Context.pdf. 

